\title{
Visuals and attention to earnings news on twitter
}

\author{
Alexander Nekrasov ${ }^{1} \cdot$ Siew Hong Teoh $^{2}$ (D) $\cdot$ Shijia Wu ${ }^{3}$
}

Accepted: 14 July 2021 /Published online: 6 August 2021

(C) The Author(s) 2021

\begin{abstract}
We propose the visual attention hypothesis that visuals in firm earnings announcements increase attention to the earnings news. We find that visuals in firms' Twitter earnings announcements are associated with more retweets, consistent with greater user engagement with announcements that have visuals. This result holds for earnings tweets sent by the same firm and on the same day in firm-level and tweet-level analyses. Consistent with managerial opportunism, firms are more likely to use visuals in their earnings tweets when performance is good but less persistent. Consistent with visuals increasin $g$ investor attention, the initial return response to earnings news is stronger and the post-announcement response is lower when visuals are used. Our evidence of a post-announcement return reversal indicates that visuals can be a double-edged sword. Furthermore, the higher earnings response coefficient from visuals is more pronounced on days with high investor distraction (when many other firms are also announcing earnings).
\end{abstract}

Keywords Visual $\cdot$ Attention $\cdot$ Salience $\cdot$ Earnings news $\cdot$ Twitter $\cdot$ Earnings response coefficients

JEL codes $\mathrm{D} 21 \cdot \mathrm{G} 12 \cdot \mathrm{G} 14 \cdot \mathrm{G} 18 \cdot \mathrm{G} 38 \cdot \mathrm{M} 41$

A picture is worth a thousand words.

Siew Hong Teoh

steoh@anderson.ucla.edu

Alexander Nekrasov

nekrasov@uic.edu

Shijia $\mathrm{Wu}$

wushijia@cuhk.edu.cn

1 University of Illinois at Chicago, Chicago, IL, USA

2 UCLA Anderson School of Management, Los Angeles, CA, USA

3 The Chinese University of Hong Kong, Shenzhen, China 


\section{Introduction}

Investor attention is a limited cognitive resource. In consequence, only a subset of investors attend to any given public release of information. The form of presentation and the media channel of a firm's announcement can affect whether and how effectively the news is processed and impounded in investors' valuations.

Recognizing the average investor's limited capability to attend to information, the Securities and Exchange Commission (SEC) has undertaken major actions to ensure that investors notice firm disclosures and that the disclosures are understandable to them so that they can process and use the information. Recognizing the importance and relevance of social media to extend information to a wider set of investors, starting in 2013 the SEC permitted companies to use social media outlets, such as Facebook and Twitter, to announce earnings news.

To help make disclosures transparent to investors, the SEC introduced the Plain Writing Initiative in 1998 and issued a guide titled A Plain English Handbook: How to Create Clear SEC Disclosure Documents (SEC 1998). ${ }^{1}$ This handbook emphasizes the importance of visuals, not just word choice and sentence structure, in making disclosures understandable to the average investor. ${ }^{2}$ Chapter 7 of the handbook emphasizes that good visual design "serves the goal of communicating the information as clearly as possible," whereas bad design "can make even a well-written document fail to communicate." According to the SEC, both what you say and how you say it matter for clear communication.

A large literature addresses the importance of disclosure readability to capital markets using textual analysis (see the survey by Li 2011; Guay, Samuels, and Taylor 2016; Bushee, Gow, and Taylor 2018). Another strand of research analyzes speech in financial communications (Mayew and Venkatachalam 2012a) and CEO signature size (Ham, Seybert, and Wang 2018). However, there has been little study of the effect of visuals on investors' understanding of public firm disclosures, and most of the studies that have been conducted were laboratory experiments. ${ }^{3}$

\footnotetext{
${ }^{1}$ The SEC also mandated plain writing in certain sections of prospectuses in 1998. In 2008, the plain writing requirement was extended also to mutual fund summary prospectuses. All federal agencies are now required to write rules in plain English, following the Federal Plain Language Guidelines after the Plain Writing Act of 2010.

${ }^{2}$ Chapter 7 of the SEC's plain writing guideline lists five design elements that aid understanding for a plainly written document: hierarchy or distinguishing levels of information, typography, layout, graphics, and color. In this paper, we focus on the graphical element because it is relatively easy to identify whether a tweet contains visuals. The handbook identifies the following as graphics: tables, charts, figures, and graphs. We also include photos and videos. We use the word "graphics" interchangeably with "visuals." We are unable to examine the other design elements (hierarchical structure, typography, layout, and color) for their contribution to clarity. There is no widely accepted standard in the neuroscience, biology, or cognitive psychology literatures for measuring these elements in a way that would map into a scale for clarity.

${ }^{3}$ Consistent with visual cues increasing perceived disclosure credibility, Asay, Libby, and Rennekamp's (2018) lab experiments find stronger reactions to good or bad news when the earnings disclosure has a CEO's photo, suggesting that the visual cue increases the perceived disclosure credibility. Elliott, Hodge, and Sedor (2012) find that experimental subjects believe online video explanations of restatements more than text explanations. Elliott, Grant, and Rennekamp (2017) find that visuals in firms' CSR reports significantly increase experimental subjects' willingness to invest in the firm. Brown, Elliott, and Grant (2019) find that experimental subjects rely more on non-GAAP earnings when earnings tweets contain a visual of non-GAAP earnings and a hyperlink to an earnings press release that prominently presents GAAP earnings. Cox, Goeij, and Campenhout (2018) find that mutual fund clients invest more optimally when key fund information (fees, past returns) are summarized visually.
} 
In this study, we examine whether, as suggested in the SEC's handbook, investors are more likely to pay attention to and effectively process the information in financial disclosures when the disclosures include visuals. We test what we call the visual attention hypothesis, which asserts that investor attention to earnings news is higher when the news disclosure includes visuals. We therefore study the effects of visuals on investor behaviors and market outcomes. Furthermore, if visuals attract investor attention, then managers may use them strategically. Thus, we also study the determinants of managers' choice to include visuals in earnings disclosures.

We study these visual attention effects using earnings announcements that are disseminated by firms via Twitter. The Twitter environment allows us to test for two types of consequences of higher investor attention. Attending to an information signal begins with awareness of the signal, followed by encoding and processing, the processes through which information is stored in memory for future retrieval. In Section 2, we discuss in greater depth the psychological motivation for our tests, and the benefits of using firm earnings announcements on Twitter to test hypotheses about visual attention from the initial and later stages of cognitive processing.

The first set of tests on the consequence of visuals focuses on the initial awareness stage of cognitive processing. A key advantage of the Twitter setting for this purpose is that it allows users who are aware of an earnings tweet to demonstrate their engagement with the tweet by "retweeting" and sharing it with their followers. Thus, we use retweets to measure user engagement with an earnings announcement, and test whether engagement is higher when the earnings announcement tweet contains visuals.

As a further corroborative test for whether visuals increase investor attention, we investigate whether visuals in earnings tweets are associated with higher Google search volume on the earnings announcement day. Past studies such as Da, Engelberg, and Gao (2011) and Drake, Roulstone, and Thornock (2012) suggest that abnormal Google search volume for a firm's stock is an attention proxy for the firm.

The second set of tests on the consequence of visuals examines whether visuals help information to be more quickly impounded into price in reaction to earnings news. In accounting, limited attention theory predicts that higher investor attention increases the sensitivity of the market price to the earnings surprise at the announcement date and decreases the post-announcement return reaction (Hirshleifer and Teoh, 2003). We therefore test whether visuals in the earnings tweet are associated with a higher earnings response coefficient (ERC) in the short announcement window, and a lower delayed reaction (PEAD). We also conduct several cross-sectional tests in settings with varying levels of investor attention. We examine whether visuals in the earnings announcement help a firm compete for investor attention on high-distraction days when many other firms are also announcing earnings. We also compare the association between visuals and ERC between high- and low-investor-interest firms (as measured using abnormal Google search volume), and between a high and a low number of retweets.

Next, we study the determinants of the managerial choice to use visuals in the earnings announcement tweet. We explore whether managers use visuals for the purpose of making earnings news announcements more informative or, alternatively, for opportunistic purposes. To do so, we test whether the use of visuals varies between good and bad earnings surprises and with the level of persistence of the earnings. Specifically, greater use of visuals when news is more persistent would be consistent 
with an informativeness incentive for managers. In contrast, greater use of visuals when news is transitory would be consistent with an opportunistic incentive.

We obtain firm tweets on earnings announcement days and use a list of keywords (see Appendix B) to identify tweets that are likely to be earnings announcement related. Our main measure of the presence of visuals is an indicator variable for whether the firm sends at least one earnings-related tweet that contains visuals (image or video) on the earnings announcement date. Our sample period covers 2011-2017, and we have a sizeable sample of 13,967 quarterly earnings announcement tweets for 679 unique firms.

For the first set of tests for the consequence of visuals, we find that a firm's earnings announcement tweets are more likely to be retweeted when there are visuals in them. This result from the firm-level test is consistent with the visual attention hypothesis. We use firm, year, and quarter fixed effects to control for unobservable firm type or other firm characteristics and time-specific characteristics that could drive differences in retweets.

We go beyond firm-level tweet analysis to the tweet-level analysis. Often, firms send multiple earnings tweets on the same earnings announcement day. This allows us to test attention to visuals in a highly controlled setting at the tweet level. Specifically, we use firm-day fixed effects to compare attention to earnings tweets with and without visuals sent by the same firm on the same day. Again, we find that earnings tweets with visuals are more likely to be retweeted than earnings tweets without visuals. The effect is large. The presence of visuals is associated with an increase in the odds of retweets by a factor of 5.67 .

We find that visuals in earnings tweets are also associated with higher abnormal Google search volume, corroborating the results from using retweets as an attention proxy. We also run additional tests that examine attention-focus and attention-distraction effects from multiple tweets by a firm on its earnings announcement day, without conditioning on visuals. We observe a focus effect at the firm level: there are more retweets about the firm when the firm sends more earnings-related tweets on the earnings announcement date. However, there is also a distraction effect, which occurs at the tweet level: the number of retweets of any given earnings tweet is lower when the firm sends more earnings-related tweets on that day. The latter result is reminiscent of the distraction effect from same-day other firm earnings announcements in Hirshleifer et al. (2009), but the signal interference here is coming from other tweets sent by the same firm.

If visuals affect investor responses to earnings news, then firms have an incentive to use them to manage investor perceptions. There is considerable variability in the use of visuals both across and within firms, which suggests that firms may indeed be engaging in such management. We test several hypotheses. First, we hypothesize that the decision to use visuals is influenced by firms' desire to highlight positive earnings news and high sales growth. Consistent with this prediction, we find some evidence suggesting that firms are more likely to use visuals in earnings-related tweets when earnings exceed market expectations and when sales growth is high.

Second, we test whether firms use the higher salience of visuals to signal more value relevant - that is, more persistent - earnings, or alternatively, to exploit temporary good performance when earnings are less persistent. Our results point to the second alternative. Managers are more likely to use visuals in earnings tweets when earnings persistence is low.

The finding that managers use visuals strategically is premised on the idea that managers perceive that the presentation format and the presentation channel affect 
investor perceptions. This raises the question of whether visuals actually do influence investors' reactions to earnings news. Limited attention theory predicts that news that is more salient results in a stronger immediate price reaction and a lower postannouncement reaction.

To test this prediction, we measure the immediate event-period reaction using stock returns over the three days around the earnings announcement. We capture the delayed reaction using returns over the three days around the next earnings announcement. Consistent with our predictions, we find that the immediate reaction to earnings news is higher and the delayed reaction is lower when firms use visuals.

It is possible that the relation between visuals and stock price reactions derives from endogeneity. The type of firms that include visuals may have more immediate price reactions to earnings for reasons other than the attention effects of visuals. To mitigate endogeneity concerns in our returns tests, (1) we use residual visuals from the regression of visuals on an expanded set of explanatory variables, and (2) we use past visuals unrelated to earnings as an instrument for the firm's ex ante propensity to use earningsrelated visuals on the earnings announcement day. We also use firm, year, and quarter fixed effects in our regressions. Still, we cannot observe all firm actions that may be correlated with the use of visuals. So, although the evidence is highly suggestive, we cannot be conclusive about causality in our returns tests.

However, further cross-sectional analyses help corroborate the inference consistent with the visual attention hypothesis. Hirshleifer et al. (2009) show that investor attention is diluted by multiple same-day announcements. We find that the effect of visuals is concentrated on days with many earnings announcements by other firms, which suggests that visuals help the firm's announcement stand out from the distracting effect of other concurrently arriving news. We also find that the positive association between visuals and ERC is more pronounced for stocks with high individual investor interest (proxied by past Google search volume) and when the visuals attract more attention (proxied by the number of retweets). Overall, these findings suggest that visuals attract investor attention to earnings news.

We are not the first to examine the capital market implications of the use of social media such as Twitter to disseminate information, including information about earnings. ${ }^{4}$ Our paper is different in two major ways. First, we examine presentation format, specifically the inclusion of visuals, in the tweet. Second, in addition to market outcomes that result after both the awareness and comprehension stages of information processing (and are the primary focus of past studies), we examine retweets as attention outcomes mostly from the initial awareness stage of information processing.

\footnotetext{
${ }^{4}$ Blankespoor, Miller, and White (2014) examine how earnings announcement tweets affect trading volume and volatility. Curtis, Richardson, and Schmardebeck (2014) measure attention using social media activity to study attention effects on the pricing of earnings news. Lee, Hutton, and Shu (2015) investigate how social media affects the capital market consequences of consumer product recall disclosures. Bartov, Faurel, and Mohanram (2018) examine whether opinions tweeted by individual twitter users just prior to a firm's earnings announcement predict the firm's announcement returns and earnings. Crowley, Huang, and Lu (2018) investigate firm discretionary choices in timing and presentation format when disseminating information on social media. Jung, Naughton, Tahoun, and Wang (2018) also examine whether firms use social media to strategically disseminate financial information and find that such dissemination is less likely when there is bad news.
} 
Our study contributes to several strands of research. By examining the determinants of firms' choice to use visuals, we contribute to the disclosure incentives literature and the growing literature on presentation attributes of disclosures, including readability, complexity, tone, and voice tone. ${ }^{5} \mathrm{We}$ further contribute by examining factors that influence investor attention. ${ }^{6}$ Unlike most studies that use indirect measures of attention, we identify attention to individual earnings-related tweets. By examining the use of visuals on Twitter and the visuals' effects on attention, our study also contributes to the emerging literature on the importance of the dissemination of earnings news on social media (Blankespoor et al. 2014; Lee et al. 2015; Bartov et al. 2018; Crowley et al. 2018; Jung et al. 2018; Teoh 2018; Guindy, Naughton, and Riordan 2020). Finally, our results have potential policy implications for regulators concerned about clear communications by firms to investors.

\section{The psychology of attention, and twitter as a channel for disseminating earnings news}

Visuals, including graphical representation of information, affect users in fundamentally different ways from text. Psychologists (see, for example, Fiske and Taylor 2016) contend that visuals are more salient and vivid than text, where salience is the extent to which a stimulus stands out relative to other stimuli in the environment and vividness is the inherent attention-getting features of a stimulus (regardless of environment). Higher salience and vividness increase awareness, the initial cognitive stage for processing an information signal.

The evolutionary development of the cognitive processing of visual information began long before the invention of writing, so it is not surprising that the human mind is better at processing visuals than text. Cognitive neuroscience and psychology research find that images are recognized, processed, and retrieved from memory much faster and more efficiently than text (e.g., Shepard 1967; Hockley 2008). The striking ability of the brain to extract conceptual information from visuals is highlighted by the fact that people can identify and remember images presented for even a tiny fraction of a second (Potter, Wyble, Hagmann, and McCourt 2014). There is also evidence that the use of visuals in information disclosures increases salience in other decision contexts in the economics literature. For example, Bertrand, Karlan, Mullainathan, Shafir, and Zinman(2010) show, in a well-known field experiment on loan offers in South Africa, that a photo of an attractive woman in an advertisement increased loan demand by about as much as a $25 \%$ reduction in the interest rate.

\footnotetext{
${ }^{5}$ For example, see Li (2008, 2011), Demers and Vega (2011), Huang, Teoh, and Zhang (2014), Mayew and Venkatachalam (2012a, b), Huang, Nekrasov, and Teoh (2018), and Levi (2015).

${ }^{6}$ For example, see Klibanoff, Lamont, and Wizman (1998), Hirshleifer and Teoh (2003), Barber and Odean (2008), Hou, Peng, and Xiong (2009), DellaVigna and Pollet (2009), Hirshleifer, Lim, and Teoh (2009), Da, Engelberg, and Gao (2011), Engelberg, Sasseville, and Williams (2012), Li and Yu (2012), Lou (2014), Yuan (2015), and Loughran and McDonald (2017).
} 
In behavioral accounting and finance, past archival tests on attention theories typically examine outcomes such as returns and trading volume. ${ }^{7}$ The past tests are generally not able to study the separate attention effects between the initial awareness stage of the cognition process and the later comprehension stage. ${ }^{8}$ We next explain the advantage of using the Twitter setting to test for awareness separately from comprehension.

Since 2013, when the SEC first granted permission for firms to disclose earnings news via social media platforms, Twitter has become a popular way for firms to communicate with investors and for investors to engage with firms and each other. The examination of retweets on Twitter provides a means of measuring user engagement with individual tweets. As Chawla, Da, Xu, and Ye 2014, (p. 2) put it, "The benefit of examining retweets is that it reveals attention on news: if you retweet something, there is no doubt you have paid attention to it and are aware of it."

We therefore hypothesize, based on the psychology of salience, that recipient attention to earnings news about a firm is higher for earnings tweets with visuals than for earnings tweets without visuals. ${ }^{9}$ The use of Twitter allows us to observe the reaction of Twitter users to the use of visuals in firm earnings tweets in a way that demonstrates awareness - the initial stage of the cognition process - as a separate observation from whether investors are processing this information effectively. A retweet demonstrates awareness even if the investor goes on to make poor use of the information in forming valuations. Our tests with returns as the dependent variable are also based on the idea that visuals raise awareness, but take the further step by examining whether visuals increase the investors' comprehension of the tweeted information, resulting in a more immediate response to earnings news.

There is evidence that supports our premise that retweets indicate higher awareness. In lab experiments, Counts and Fisher (2011), using eyeball tracking, find that subjects who retweet look longer at the Twitter message and can better recall its content. ${ }^{10}$ Additionally, retweets increase the reach of the earnings news, so visuals can also increase attention outcomes from the wider dissemination of the news.

\footnotetext{
7 Several studies use internet search and download patterns to measure attention (e.g., Da, Engelberg, and Gao 2011; Loughran and McDonald 2017; Zhu 2018).

${ }^{8}$ Blankespoor, deHaan, Wertz, and Zhu (2019) study awareness of earnings news in a different setting where some firms have automated news articles generated by the news media from an earnings announcement. They assume that having automated news articles increases the reach and therefore awareness of the earnings news. They find that the trading response to earnings news does not increase with higher investor awareness in the presence of automated news articles in a difference-in-differences design. Our test is different in that we study visuals as the awareness trigger, and we measure the awareness outcome using retweets, and so we do not require that trading response is correlated with the earnings news.

${ }^{9}$ The predicted effect of visuals for earnings tweets is in line with the effect of visuals for non-financial tweets (https://business.twitter.com/en/blog/7-tips-creating-engaging-content-every-day.html). In the general context, visuals may be associated with entertainment value or other emotional responses. In contrast, the alternative maintained assumption of perfect rationality is that the presentation format is irrelevant. For this reason, the effects of visuals for earnings news are useful to investigate.

${ }^{10}$ In unreported tests (available on request), we find that retweets are associated with Google Search volume, which is an attention proxy used in prior research (Da et al. 2011; Drake et al. 2012). Furthermore, Rakowski, Shirley, and Stark (2021) find that retweets are associated with higher immediate returns, which is consistent with retweets proxying for attention. Our returns test is different in that we condition on whether earnings announcements tweets have visuals. It is possible that tweet recipients who pay attention do not retweet the tweet. This situation introduces noise to retweets as an attention proxy and therefore biases against our finding results consistent with the attention predictions.
} 
Content in the SEC's handbook on plain-writing disclosures suggests that the commission believes in the effectiveness of visuals in conveying information. For example, Chapter 7 states, "Graphics often illuminate information more clearly and quickly than text." In the same chapter, the SEC recommends Tufte's $(1983,2001)$ book The Visual Display of Quantitative Information and cites it as follows.

At its best, graphics are instruments for reasoning about quantitative information. Often the most effective way to describe, explore, and summarize a set of numbers - even a very large set - is to look at pictures of those numbers. Furthermore, of all methods for analyzing and communicating statistical information, well-designed data graphics are usually the simplest and at the same time the most powerful. (p. 9).

Graphical excellence is that which gives to the viewer the greatest number of ideas in the shortest time with the least ink in the smallest space. (p. 51).

In summary, the SEC advocates the use of visuals in disclosures to ease understanding, which is the agency's overriding goal for plain English communication between public firms and their investors.

The format of earnings dissemination on social media is unregulated. Therefore, the use of visuals to publicize earnings news varies widely across firms. Appendix A provides several examples. Some firms do not use visuals and only send simple text tweets. Others use visuals that contain performance measures, charts, quotes from the management, or images that highlight the release of the earnings announcement. In some cases, the visual is a video message that plays automatically (though the audio part requires clicking to activate) and explains key results. In this paper, we focus on the incidence of visuals to examine the average salience effect of visuals. We leave the investigation of the effects of different types of visuals and their interactions with the textual content of earnings announcement tweets to future research.

\section{Data and variable measurement}

\subsection{Sample data}

Twitter was created in October 2006 and initially only allowed users to send text tweets that contained up to 140 characters. Beginning in June 2011, Twitter allowed users to supplement text tweets with visuals (still images and videos). Given our interest in firms' use of visuals, we begin the sample period in June 2011. The sample ends in December 2017, the last month for which we have the necessary Twitter and financial data. We obtain analyst forecasts and actual earnings numbers from I/B/E/S, company financial data from Compustat, and stock prices and returns from CRSP.

Table 1 Panel A presents details of the sample selection. We begin with the sample of firms included in the S\&P 1500 index. We exclude 345 firms without an official Twitter account as of February 2018, when we began collecting Twitter handles for the firms. For the 1155 firms with Twitter accounts, we collect all available tweets that firms send to their followers on earnings announcement dates over the sample period. If a firm has multiple Twitter accounts, we collect tweets from all accounts, including 
those that belong specifically to investor relations (IR). From this set, we retain tweets related to earnings announcements by using earnings-related keywords, which are detailed in Appendix B. ${ }^{11}$ This process eliminates 405 firms that did not send any earnings-announcement-related tweets on the earnings announcement date during our sample period. Finally, we exclude observations that have missing stock returns or that lack any of the necessary financial data or analyst forecasts. Our final sample contains 13,967 earnings-announcement-related tweets sent over 4928 firm-quarter earningsannouncement days for 679 unique firms.

Note that we restrict our sample to only earnings-announcements tweets. Doing so avoids the need to consider why firms send tweets unrelated to earnings announcements and why users pay attention to those tweets, which are nontrivial questions but outside of the scope of our paper. Limiting the analysis to earnings-announcement tweets also avoids the need to model firms' choice to announce earnings news on Twitter, which is a topic of prior work (e.g., Blankespoor et al. 2014; Crowley et al. 2018; Jung et al. 2018). Since all tweets in our sample are earnings related, there is no need for an indicator of earnings-related tweet or its interaction with the visual indicator.

Panel B of Table 1 reports the distribution of the sample and visuals across industries, using the 12 Fama-French industry classification. ${ }^{12}$ The industries with the most firm-quarter observations are finance, business equipment, healthcare, medical equipment, and drugs. The industries with the highest percentage of quarters with earnings-announcement-related visual tweets are consumer durables, telephone and television transmission, and consumer non-durables, suggesting that consumerfocused businesses are more likely to use visuals. While there is significant variation in the distribution of the sample and visuals across industries, no single industry dominates the sample.

\subsection{Measures of twitter visuals and user engagement}

Our main measure of the firm's use of visuals when disseminating earnings news on Twitter is a firm-level indicator, VISUALS $S_{j t}$, which equals 1 if firm $j$ sends at least one earnings-announcement-related tweet that contains visuals (still images or videos) on the earnings announcement date for quarter $t$ and 0 otherwise. At the level of individual tweets, we use an indicator variable, VISUALS $S_{i j t, t w e e t . l e v e l}$, which equals 1 if earningsannouncement-related tweet $i$ on the earnings announcement date for firm $j$ quarter $t$ contains visuals and 0 otherwise. To control for endogeneity of firms' choice of visuals, we also use a residual visuals variable estimated from a first-stage regression and an instrumental variable (IV) based on past visuals unrelated to earnings, which we discuss in Subsections 3.4 and 3.6, respectively.

Firms often disseminate earnings news by sending tweets that contain quantitative items or web links to external websites. The quantitative items usually relate to firm performance, and the web links direct investors to the earnings press release on the

\footnotetext{
${ }^{11}$ To assess the accuracy of our approach, we manually check a random sample of 500 tweets classified as earnings-related and find that 473 tweets $(94.6 \%)$ are classified correctly, suggesting that our approach is reasonably accurate.

${ }^{12}$ Available from Ken French at http://mba.tuck.dartmouth.edu/pages/faculty/ken.french/data_library.html.
} 


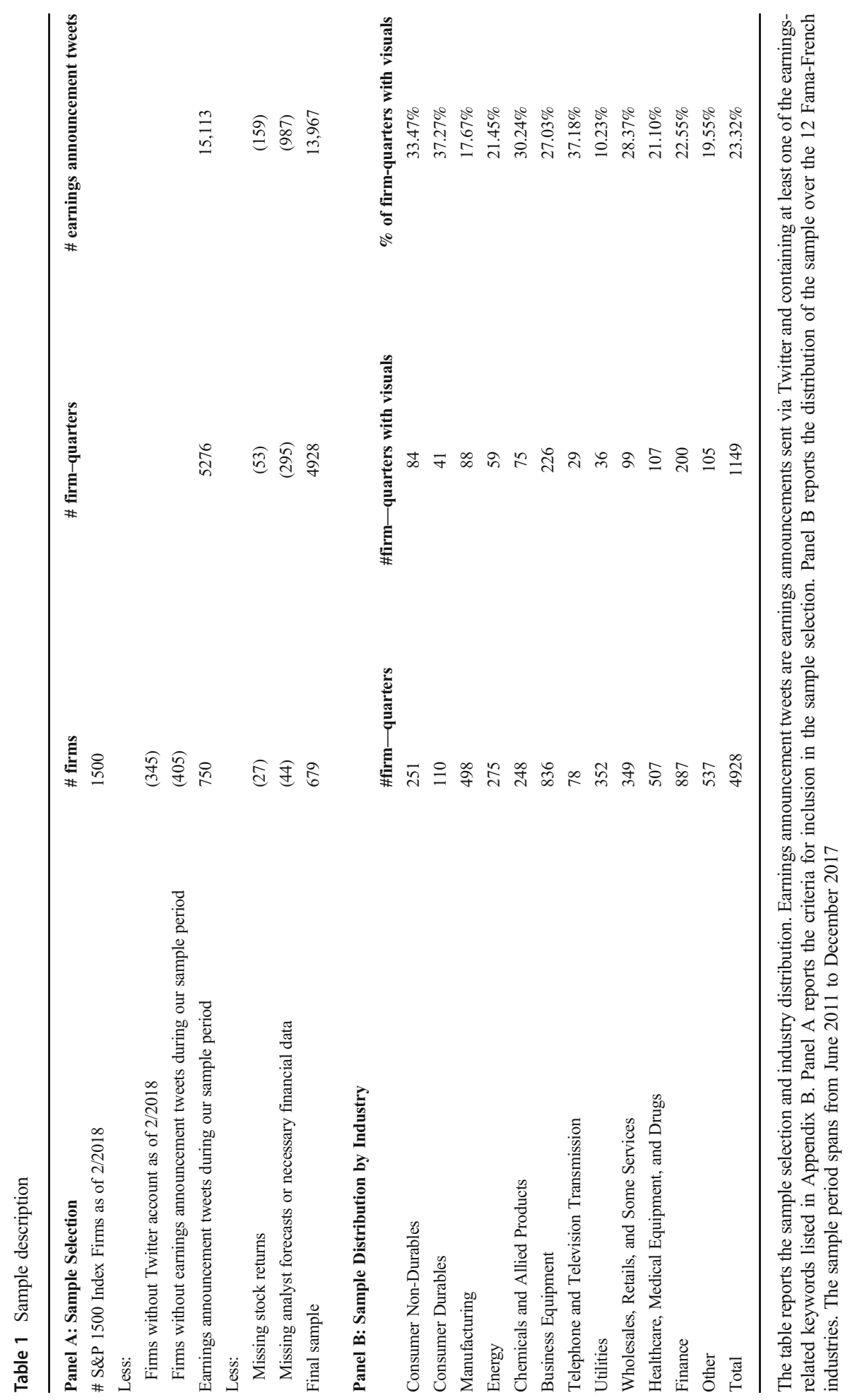


firm's investor relations website. Both may influence how investors process the news. To control for effects from these items, we use firm-level indicator variables, QUANT.ITEMS $_{j t}\left(\right.$ WEB.LINKS $\left._{j t}\right)$, which equal 1 if firm $j$ 's earnings announcement tweet for quarter $t$ contains at least one quantitative item (web link) and 0 otherwise. ${ }^{13}$ Two equivalent indicators, QUANT.ITEMS $S_{\text {tweet.level }}$ and WEB.LINKS $S_{\text {tweet.level, }}$ are defined in a similar way for the use of quantitative items and web links, respectively, at the individual tweet level.

Twitter users can demonstrate their engagement with a received tweet by retweeting it to their followers. Retweeting increases the dissemination beyond the original recipients of the tweet. The number of retweets is displayed with the tweet and can signal that other people found the tweet relevant. Thus, retweets potentially increase the reach of the tweet by attracting attention from people who typically do not follow firm news.

For our research, we are interested in retweets as a proxy of user engagement with earnings announcement tweets. We define a firm-level indicator variable, RETWEETS , $_{j}$, which equals 1 if at least one earnings-related tweet posted by firm $j$ on the earnings announcement date for quarter $t$ was retweeted and 0 otherwise. The indicator of

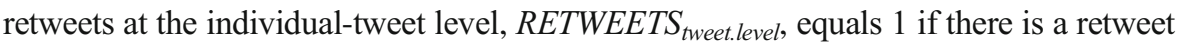
at the tweet level and 0 otherwise. ${ }^{14}$

Finally, we include the following variables to control for the volume of information on the same day as the earnings announcement: EA.TWEETS $S_{j t}$ is the number of earnings-announcement-related tweets firm $j$ sends on the earnings announcement date for quarter $t$. $L E N G T H_{j t}$ is the natural logarithm of the average number of characters of the earnings-related tweets on the earnings announcement date for quarter $t$. FOLLOWERS $S_{j}$ is the natural logarithm of the number of Twitter users that follow firm $j$ as of March 31, 2018, when we completed scraping the data on firm followers. The measure is calculated at a point in time because time-series data on the number of followers are not available.

\subsection{Other variables}

Aside from Twitter measures, the dependent variables for the returns consequence tests are the following: $C A R(-1,+1)$ is the cumulative abnormal return over the three-day window centered on the earnings announcement date, where daily abnormal returns are raw returns minus the market value-weighted return; and CAR $(-1,+1)_{\text {NEXT.QTR }}$ is the cumulative abnormal return, $C A R(-1,+1)$, around the next-quarter earnings announcement.

The set of other independent variables and cross-sectional test variables include the following: Firm size, SIZE, is the natural logarithm of the market value of equity at the

\footnotetext{
13 To increase the likelihood that quantitative items relate to performance, we require that the item be preceded or followed by one of the following characters or words: $\$$, dollar, dollars, $\%$, percent, cents, cent, c, thousand, $\mathrm{k}$, million, $\mathrm{m}, \mathrm{mm}, \mathrm{mn}$, mill, billion, $\mathrm{b}$, bn, basis, bps.

${ }_{14}$ The available data does not allow us to remove retweets that are posted after the earnings announcement date. This measurement noise should not be large, because retweets concentrate at the initial tweet date. For example, $75 \%$ of all retweets occur within the day (Chun, Kwak, Eom, Ahn, Moon, and Jeong 2008, Kwak, Lee, Park, and Moon 2010). Furthermore, the measurement error likely will bias against our finding a higher announcement-day ERC and a lower PEAD if the retweets increase attention and occur after the announcement date.
} 
end of the previous fiscal quarter, to control for risk. BTM is the book-to-market ratio at the end of the previous fiscal quarter. An indicator of positive earnings news, POS.SURP, is defined as 1 if actual earnings for the quarter are greater than or equal to the consensus analyst forecast and 0 otherwise. (The consensus analyst forecast is the mean of the most recent forecasts made by individual analysts.) Unexpected earnings, $S U E$, is actual quarterly earnings as reported by $\mathrm{I} / \mathrm{B} / \mathrm{E} / \mathrm{S}$ minus the consensus analyst forecast, scaled by stock price at the end of the previous fiscal quarter. $R S U E$, is the decile rank of $S U E$ scaled, such that it varies from 0 (for the bottom decile) to 1 (for the top decile). Sales growth, GROWTH, is calculated as the percentage change in quarterly sales from the same quarter last year. $E A R N$ is quarterly earnings before extraordinary items scaled by average total assets. Analyst following, ANA.FOLLOW, is the natural logarithm of one plus the number of analysts that have outstanding earnings forecast for the firm for the quarter. Institutional ownership, INST.OWN, is the fraction of firm shares owned by institutional investors. $N R A N K$ is the quartile rank of the number of same-day earnings announcements by other firms. AB.SEARCH is the abnormal Google search volume for the firm for the day, following Drake et al. (2012). And MEDIA.COVERAGE is the natural logarithm of one plus the number of news articles for the firm for the day, where the number of articles is obtained from Bloomberg.

\section{Empirical results}

\subsection{Descriptive statistics}

Table 2 Panel A reports descriptive statistics for variables related to Twitter activity at the firm-quarter level. The mean of 0.233 for the visual indicator variable, VISUALS, indicates that $23.3 \%$ of firm-quarter earnings announcements contain visuals. On average, $31.0 \%$ of firm-quarter earnings announcements contain dollar-value or percent magnitudes of quantitative items, and $94.4 \%$ include a web link. Earnings-related tweets are retweeted for $65.8 \%$ of the firm-quarter observations. The mean number of retweets of earnings-related tweets is 8.875 . The mean number of retweets of earnings-related tweets is 31.35 when firms use visuals and 7.00 when firms do not use visuals (untabulated), suggesting that visuals have large effects on retweets and therefore could have economically significant capital market outcomes.

Panel B of Table 2 provides descriptive statistics for variables related to Twitter activity at the tweet level. The statistics indicate that $16.2 \%$ of earnings-announcementrelated tweets contain visuals, $27.4 \%$ contain quantitative items, and $70.4 \%$ contain web links. On average, $54.7 \%$ of earnings-announcement-related tweets are retweeted. The mean number of retweets of a given earnings-related tweet is 3.173.

Panel $\mathrm{C}$ of Table 2 reports descriptive statistics for financial variables. The mean POS.SURP is 0.672 , indicating that earnings exceed the consensus forecast in $67.2 \%$ of earnings announcements. Given our use of S\&P 1500 firms with Twitter activity, firms in our sample are relatively large, with a mean (median) market capitalization of $\$ 25,845.5(\$ 8,594.6)$ million. The mean (median) number of analysts following the firm is 13.52 (13). The mean (median) number of same-day earnings announcements is 73.25 (70). 
Table 2 Summary statistics

\begin{tabular}{|c|c|c|c|c|c|c|c|}
\hline Variable & Mean & StdDev & $\mathrm{P} 10$ & $\mathrm{P} 25$ & Median & P75 & P90 \\
\hline \multicolumn{8}{|c|}{ Panel A: Twitter Variables at the Firm-Quarter Level } \\
\hline VISUALS & 0.233 & 0.423 & 0 & 0 & 0 & 0 & 1 \\
\hline VISUALS.RES & 0.000 & 0.358 & -0.387 & -0.254 & -0.079 & 0.164 & 0.591 \\
\hline QUANT.ITEMS & 0.310 & 0.463 & 0 & 0 & 0 & 1 & 1 \\
\hline WEB.LINKS & 0.944 & 0.230 & 1 & 1 & 1 & 1 & 1 \\
\hline RETWEETS & 0.658 & 0.474 & 0 & 0 & 1 & 1 & 1 \\
\hline \#RETWEETS & 8.875 & 35.169 & 0 & 0 & 1 & 5 & 15 \\
\hline FOLLOWERS & 8.888 & 1.779 & 6.645 & 7.575 & 8.821 & 9.995 & 11.402 \\
\hline EA.TWEETS & 2.868 & 5.848 & 1 & 1 & 1 & 2 & 6 \\
\hline$L E N G T H$ & 4.400 & 0.336 & 3.932 & 4.174 & 4.443 & 4.654 & 4.762 \\
\hline
\end{tabular}

Panel B: Twitter Variables at the Tweet Level

$\begin{array}{llllllll}\text { VISUALS }_{\text {tweet.level }} & 0.162 & 0.368 & 0 & 0 & 0 & 0 & 1 \\ \text { QUANT.ITEMS }_{\text {tweet.level }} & 0.274 & 0.446 & 0 & 0 & 0 & 1 & 1 \\ \text { WEB.LINKS }_{\text {tweet.level }} & 0.704 & 0.456 & 0 & 0 & 1 & 1 & 1 \\ \text { RETWEETS }_{\text {tweet.level }} & 0.547 & 0.497 & 0 & 0 & 1 & 1 & 1 \\ \text { \#RETWEETS }_{\text {tweet.level }} & 3.173 & 10.275 & 0 & 0 & 1 & 3 & 7 \\ \text { LENGTH }_{\text {tweet.level }} & 4.483 & 0.392 & 3.951 & 4.234 & 4.533 & 4.745 & 4.920\end{array}$

Panel C: Other Variables

$\begin{array}{llllllll}\text { POS.SURP } & 0.672 & 0.469 & 0 & 0 & 1 & 1 & 1 \\ \text { SUE } & 0.001 & 0.005 & -0.002 & 0 & 0.000 & 0.002 & 0.004 \\ \text { SIZE } & 8.983 & 1.637 & 5.217 & 7.807 & 9.059 & 10.152 & 12.382 \\ \text { Mkt Cap } & 25,845.5 & 46,661.6 & 900.6 & 2,458.2 & 8,594.6 & 25,645.5 & 69,109.8 \\ \text { GROWTH } & 0.061 & 0.197 & -0.115 & -0.024 & 0.042 & 0.121 & 0.248 \\ \text { STD.GROWTH } & 0.113 & 0.129 & 0.024 & 0.038 & 0.069 & 0.133 & 0.260 \\ \text { NEG.GROWTH } & 0.327 & 0.469 & 0 & 0 & 0 & 1 & 1 \\ \text { BTM } & 0.446 & 0.329 & 0.098 & 0.211 & 0.375 & 0.617 & 0.864 \\ \text { ANA.FOLLOW } & 2.513 & 0.613 & 0.693 & 2.079 & 2.639 & 2.996 & 3.526 \\ \text { \#ANALYSTS } & 13.52 & 7.51 & 4 & 7 & 13 & 19 & 24 \\ \text { EARN } & 0.014 & 0.021 & -0.003 & 0.004 & 0.012 & 0.023 & 0.036 \\ \text { STD.EARN } & 0.011 & 0.015 & 0.002 & 0.003 & 0.006 & 0.012 & 0.025 \\ \text { LOSS } & 0.128 & 0.334 & 0 & 0 & 0 & 0 & 1 \\ \text { INST.OWN } & 0.780 & 0.202 & 0.601 & 0.709 & 0.817 & 0.914 & 0.982 \\ \text { \#EA } & 73.250 & 48.173 & 10 & 30 & 70 & 113 & 134 \\ \text { CAR(-1,+1) } & 0.001 & 0.067 & -0.069 & -0.029 & 0.001 & 0.034 & 0.073 \\ \text { CAR(-1,+1) } & 0.001 & 0.068 & -0.069 & -0.031 & -0.000 & 0.032 & 0.071 \\ \text { AB.SEARCH } & 0.249 & 0.823 & -0.286 & -0.083 & 0.031 & 0.275 & 1.116 \\ \text { MEDIA.COVERAGE } & 5.175 & 1.510 & 5.375 & 4.263 & 4.836 & 5.916 & 6.522\end{array}$

The table provides descriptive statistics. Panel A reports descriptive statistics for Twitter variables at the firmquarter level. Panel B reports descriptive statistics for Twitter variables at the tweet level. Descriptive statistics for other variables are reported in Panel C. Mkt Cap is the market value of equity and $S I Z E$ is $\ln (\mathrm{mkt}$ cap). \#ANALYSTS is the number of analysts following the firm. \#EA is the number of same-day earnings announcements. All other variables are as defined in Appendix C 


\subsection{Attention to visuals}

Limited attention theory predicts that salient information attracts greater investor attention (Hirshleifer and Teoh 2003). Applying this to the context of earnings news disseminated on Twitter and the higher salience of visuals versus text-only tweets, we predict the following at the firm level.

Visual attention hypothesis: attention to earnings announcement tweets, as proxied by retweets, is higher when earnings news is disseminated on Twitter with visuals.

As explained earlier, we proxy for attention using retweets at the firm and tweet levels. When a user retweets an earnings-related tweet, it means the user has noticed and engaged with the tweet. Thus, compared to other indirect measures of attention, such as returns and trading volume, retweets allow us to gauge user engagement with individual earnings announcement tweet.

To test how attention to the earnings news is influenced by visuals at the firm level, we estimate the following logistic regression at the firm-quarter level.

$$
\begin{aligned}
\text { RETWEETS }_{j t}= & \alpha+\beta_{1} \text { VISUALS }_{\mathrm{jt}}+\beta_{2} \text { QUANT.ITEMS }_{\mathrm{jt}} \\
& +\beta_{3} \text { WEB.LINKS }_{\mathrm{jt}}+\beta_{4} \text { SIZE }_{\mathrm{jt}}+\beta_{5} \text { ANA.FOLLOW }_{\mathrm{jt}} \\
& +\beta_{6} \text { POS.SURP }_{\mathrm{jt}}+\beta_{7} \text { GROWTH }_{\mathrm{jt}}+\beta_{8} \text { BTM }_{\mathrm{jt}} \\
& +\beta_{9} \text { INST.OWN }_{\mathrm{jt}}+\beta_{10} \text { EA.TWEETS }_{\mathrm{jt}}+\beta_{11} \text { LENGTH }_{\mathrm{jt}} \\
& +\beta_{12} \text { MEDIA.COVERAGE }_{\mathrm{jt}}+\text { Firm FE }+ \text { Year FE } \\
& + \text { Quarter FE }+\varepsilon_{\mathrm{jt}},
\end{aligned}
$$

where subscripts $j t$ denote firm $j$ quarter $t$; the indicator of retweets of earningsannouncement-related tweets (RETWEETS) is used to proxy for attention to the earnings news; and VISUALS is the indicator of the firm's use of visuals to disseminate the earnings news. We include firm, year, and quarter fixed effects to control for unobservable firm type or other firm characteristics and time-specific effects in retweets. If visuals increase attention to the earnings news, the coefficient $\beta_{1}$ should be positive. All variables are as defined in Section 2.

We use firm size (SIZE) and analyst following (ANA.FOLLOW) to control for information environment. We include the positive earnings surprise indicator (POS.SURP) to proxy for good earnings news, sales growth (GROWTH) to proxy for current growth, and the book-to-market ratio $(B T M)$ to control for future growth opportunities. We include institutional ownership (INST.OWN) to control for investor base; the number of the firm's followers (FOLLOWERS) to control for the size of the firm's Twitter audience; the number of earnings-announcement-related tweets (EA.TWEETS) and the average length of the earnings-announcement-related tweets (LENGTH) to control for the volume of the dissemination of earnings news on Twitter; and the number of articles about the firm (MEDIA.COVERAGE) to control for the media coverage.

We also include the indicator of the firm's use of quantitative items in earningsannouncement-related tweets (QUANT.ITEM), since prior findings suggest that 
quantitative items attract investor attention (Huang, Nekrasov, and Teoh 2018). We include the indicator of the firm's use of web links (WEB.LINK). Whether web links attract investor attention is of interest because Blankespoor, Miller, and White (2014) find that the dissemination of links to earnings press releases can reduce information asymmetry.

To test the effect of visuals at the tweet level, we estimate the following regression across individual tweets.

$$
\begin{aligned}
& \text { RETWEETS }_{i j t, t w e e t . l e v e l}=\alpha+\beta_{1} \text { VISUALS }_{i j t, \text { tweet.level }} \\
& +\beta_{2} \text { QUANT.ITEMS }{ }_{i j t, \text { tweet.level }} \\
& +\beta_{3} \text { WEB.LINKS } S_{i j t, t w e e t . l e v e l}+\beta_{4} \text { SIZE }_{j t} \\
& +\beta_{5} \text { ANA.FOLLOW }{ }_{j t}+\beta_{6} \text { POS.SURP } j t \\
& +\beta_{7} \text { GROWTH }_{j t}+\beta_{8} \text { BTM }_{j t}+\beta_{9} \text { INST.OWN } N_{j t} \\
& +\beta_{10} \text { EA.TWEETS }_{j t}+\beta_{11} \text { LENGTH }_{i j t, \text { tweet.level }} \\
& +\beta_{12} \text { MEDIA.COVERAGE } E_{j t}+\text { Firm FE }+ \text { Year FE } \\
& + \text { Quarter } F E+\varepsilon_{j t} \text {, }
\end{aligned}
$$

where subscripts $i j t$ denote tweet $i$ firm $j$ quarter $t$. The subscript tweet.level denotes variables measured at the level of the individual tweet, and the remaining variables are measured at the firm level.

Firms often send multiple earnings tweets on the earnings announcement day. These firm days provide us a tight setting for testing the visual attention hypothesis. We compare retweets of earnings tweets with visuals and earnings tweets without visuals sent by the same firm on the same day. To this end, we estimate the following regression at the individual tweet level with firm-day fixed effects.

$$
\begin{aligned}
\text { RETWEETS }_{i j t, t w e e t . l e v e l}= & \alpha+\beta_{1} \text { VISUALS }_{i j t, t w e e t . l e v e l} \\
& +\beta_{2} \text { QUANT.ITEMS } \\
& +\beta_{3 j t, t w e e t . l e v e l} \\
& + \text { WEBrm-LINKS } S_{i j t, t w e e t . l e v e l}+\beta_{11} \text { LENGTH }_{i j t, t w e e t . l e v e l}
\end{aligned}
$$

where we include only tweet-level variables because firm-day fixed effects subsume all firm-level variables.

Table 3 Panel A reports the results of estimating the firm-quarter model (1a). Consistent with the hypothesis that visuals attract attention to the earnings news, the marginal effect of VISUALS is positive and significant with an associated Z-statistic of 3.61. The effect is economically meaningful. The coefficient on VISUALS indicates that the odds of retweets increase 2.16 times when the firm uses visuals $(\exp (0.771 * 1)=$ 2.16). The marginal effect indicates that, with other variables held at their means, the probability of retweets increases by $12.7 \%$ when the firm uses visuals. 
Table 3 Attention to visuals

Dependent Variable

\begin{tabular}{lll}
\hline RETWEETS & Marginal Effect
\end{tabular}

Panel A: Firm-Level Analysis - Within-Firm Variation

$\begin{array}{llll}\text { VISUALS } & 0.771 & 0.127 & 3.61 * * * \\ \text { QUANT.ITEMS } & 0.331 & 0.055 & 2.03 * * \\ \text { WEB.LINKS } & 0.286 & 0.047 & 1.01 \\ \text { SIZE } & 0.415 & 0.068 & 1.48 \\ \text { ANA.FOLLOW } & 0.141 & 0.023 & 0.46 \\ \text { POS.SURP } & 0.154 & 0.025 & 1.44 \\ \text { GROWTH } & 0.118 & 0.019 & 0.43 \\ \text { BTM } & -0.004 & -0.001 & -0.01 \\ \text { INST.OWN } & -0.858 & -0.142 & -0.99 \\ \text { EA.TWEETS } & 1.183 & 0.195 & 6.21 * * * \\ \text { LENGTH } & 0.660 & 0.109 & 3.09 * * * \\ \text { MEDIA.COVERAGE } & -0.005 & -0.001 & -0.06\end{array}$

Fixed Effects

Observations

Firm, Year, Quarter

Pseudo-R ${ }^{2}$

$26.74 \%$

Panel B: Analysis of Individual Tweets Within Firm

\section{Dependent Variable}

RETWEETS $_{\text {tweet.level }}$

VISUALS
QUEeet.level
WEB.LINKSTS
SIZEeet.level
tweet.level

ANA.FOLLOW

POS.SURP

GROWTH

BTM

INST.OWN

EA.TWEETS

${ }_{L E N G T H} H_{\text {tweet.level }}$

MEDIA.COVERAGE

Fixed Effects

Observations

Pseudo- $R^{2}$
1.006

0.249

$-0.082$

0.301

0.242

0.048

$-0.200$

0.380

$-0.681$

$-0.505$

0.292

$-0.019$

Firm, Year, Quarter

10,150

$28.71 \%$

\section{Marginal Effect}

0.165

0.041

$-0.013$

0.049

0.040

0.008

$-0.033$

0.062

$-0.112$

$-0.083$

0.048

$-0.003$
Z-stat

$7.88 * * *$

$3.34 * * *$

$-0.66$

1.37

1.10

0.49

$-0.79$

1.35

$-1.47$

$-6.97 * * *$

$2.75^{* * * *}$

$-0.35$

Panel C: Analysis of Individual Tweets Within the Same Firm and Day

\begin{tabular}{|c|c|c|c|}
\hline VISUALS $S_{\text {tweet.level }}$ & 1.736 & 0.308 & $8.91 * * *$ \\
\hline QUANT.ITEMS $S_{\text {tweet.level }}$ & 0.329 & 0.058 & $3.40 * * *$ \\
\hline WEB.LINKS $S_{\text {tweet.level }}$ & 0.074 & 0.013 & 0.53 \\
\hline
\end{tabular}


Table 3 (continued)

\begin{tabular}{llll}
\hline & \multicolumn{2}{l}{ Dependent Variable } & \\
\cline { 2 - 4 } & RETWEETS & Marginal Effect & Z-stat \\
\hline LENGTH tweet.level $_{\text {Fixed Effects }}$ & 0.264 & 0.047 & $1.90^{*}$ \\
Observations & Firm-Day & & \\
Pseudo- $R^{2}$ & 6267 & & \\
\hline
\end{tabular}

Panel A reports the results of estimating logistic regression (1a) at the firm-quarter level with firm, year, and quarter fixed effects. The dependent variable is the indicator of retweets, RETWEETS. VISUALS (QUANT.ITEMS, WEB.LINKS) is the indicator of the firm's use of visuals (quantitative items, web links) in earnings-announcement-related tweets. Panel B reports the results of estimating the logistic regression (1b) at the level of individual tweets with firm, year, and quarter fixed effects. Panel C reports the results of estimating the logistic regression (1c) at the level of individual tweets with firm-day fixed effects. All other variables are as defined in Appendix C. Standard errors are clustered by firm. ***, **, and * indicate statistical significance at the $1 \%, 5 \%$, and $10 \%$ levels, respectively (two-tailed tests)

With regard to the control variables, the results indicate that the use of quantitative items, QUANT.ITEMS, is positive and significant, suggesting that users pay greater attention to earnings news when the firm uses quantitative items. This is consistent with the finding of Huang et al. (2018) that quantification of headlines leads to stronger investor reaction to earnings news. In contrast, the use of web links, WEB.LINKS, is not significantly associated with retweets, suggesting that links do not draw greater attention. The positive and significant LENGTH suggests that longer (but still below the 140-character limit) tweets receive greater attention. We defer discussion of the results for EA.TWEETS until after we discuss Panel B results.

Panel B of Table 3 reports the results of estimating the tweet-level model (1b). These results are similar to the findings from the firm-level analysis. VISUALS $S_{\text {tweet.level }}$ is positive and significant. The odds of retweets of an earnings tweet are 2.73 times higher when the tweet has a visual $\left(\exp \left(1.006^{*} 1\right)=2.73\right)$.

Turning to the interpretation of the coefficients on EA.TWEETS in Panels A and B, we see that the marginal effect is positive in the Panel A firm-level regressions and negative in the tweet-level regression. The Panel A results are consistent with an attention-focus effect, in which many tweets sent by the announcing firm on the day of the announcement attract attention to the firm itself. The cumulative attention to all earnings-related tweets increases with the number of tweets, which draws attention to the firm. In contrast, the Panel B results show an opposite effect - one of attention dilution. When attention is finite, attention to any individual earnings-related tweet is diluted when many earningsrelated tweets are sent by the firm on that day. In other words, the volume of other tweets on the same day distracts attention from any specific tweet. This is reminiscent of the distraction effect of Hirshleifer et al. (2009), in which investor attention to a specific firm is distracted by many same-day earnings announcements by other firms. A key difference in our study is that attention is distracted by tweets by the same firm.

An alternative potential explanation for the negative effect of EA.TWEETS in the tweet-level regression is that firms send the same information in multiple tweets to extend their audience reach. If so, recipients have little incentive to retweet multiple messages containing the same information. To address this concern, we restrict the 
sample of multiple tweets to only those containing dissimilar information. We gauge the similarity of the textual information in the tweets using the cosine similarity measure (e.g., Merkley 2014; Brown, Tian, and Tucker 2018; Madsen and McMullin 2020). We rerun the regression in Panel B restricting the sample to only tweets in the bottom quartile of the cosine similarity distribution. The untabulated results show that the negative coefficient on EA.TWEETS is robust in this sample of dissimilar tweets, consistent with same-day multiple tweets having an attention-dilution effect.

Table 3 Panel $\mathrm{C}$ shows the results of estimating regression (1c), which isolates variation in visuals within the same firm and day. The results show a strong association between visuals and retweets. Notably, the coefficient on VISUALS becomes larger after controlling for firm-day fixed effects. The odds of retweets are 5.67 times higher when an earnings tweet has a visual $(\exp (1.736 * 1)=5.67)$.

\subsection{Visuals and Google search volume}

To corroborate our previous findings for the visual attention hypothesis (in which retweets were used to measure attention), we conduct an alternative test that associates visuals with an attention proxy from the past literature. Previous studies, such as Da et al. (2011) and Drake et al. (2012), use the abnormal volume of Google searches for the firm's ticker symbol around the earnings announcement to measure investor attention. The idea behind this measure is that market participants are paying attention to the firm when they search for information on its stock. If visuals attract attention and prompt searches for additional information on the stock, we expect a positive association between visuals and abnormal Google search volume.

To test this relation, we estimate the following regression at the firm-quarter level.

$$
\begin{aligned}
\text { AB.SEARCH }_{j t}= & \alpha+\beta_{1} \text { VISUALS }_{j t}+\beta_{2} \text { QUANT.ITEMS }_{j t}+\beta_{3} \text { WEB.LINKS }_{j t} \\
& +\beta_{4} \text { SIZE }_{j t}+\beta_{5} \text { ANA.FOLLOW } \\
& +\beta_{6} \text { POS.SURP }_{j t} \\
& +\beta_{7} \text { GROWTH }_{j t}+\beta_{8} \text { BTM }_{j t}+\beta_{9} \text { INST.OWN }_{j t} \\
& +\beta_{10} \text { EA.TWEETS }_{j t}+\beta_{11} \text { LENGTH }_{j t} \\
& +\beta_{12} \text { MEDIA.COVERAGE } \\
& +\beta_{14} \text { NRANK }_{j t} \\
& +\beta_{15} \text { Lagged AB.SEARCH } \\
& + \text { Firm FE }+ \text { Year FE } \\
& + \text { Quarter FE }+\varepsilon_{j t},
\end{aligned}
$$

where AB.SEARCH is the abnormal Google search volume for the firm's stock symbol on the earnings announcement day, following Drake et al. (2012). All variables are as defined in Section 2. We also examine an additional variable, Past non-earningsrelated visuals, which is the quartile rank of the total number of visuals across all non-earnings-related tweets over the trading days $(-15,-8)$ prior to the earnings announcement date. We use this variable as an instrumental variable for VISUALS in Subsection 4.6, and we defer discussion of the results for this variable to that subsection. 
Table 4 Visuals and abnormal Google search volume

\begin{tabular}{|c|c|c|c|c|}
\hline & \multicolumn{4}{|c|}{ Dependent Variable } \\
\hline & AB.SEARCH & $p$ value & AB.SEARCH & $p$ value \\
\hline VISUALS & $0.068^{*}$ & 0.062 & $0.069 *$ & 0.060 \\
\hline QUANT.ITEMS & -0.035 & 0.230 & -0.032 & 0.354 \\
\hline WEB.LINKS & -0.005 & 0.924 & -0.023 & 0.704 \\
\hline SIZE & $0.125^{* *}$ & 0.011 & $0.119 * *$ & 0.013 \\
\hline ANA.FOLLOW & -0.024 & 0.676 & -0.025 & 0.667 \\
\hline POS.SURP & -0.015 & 0.566 & 0.018 & 0.555 \\
\hline GROWTH & $0.139 * *$ & 0.030 & $0.234 * * *$ & 0.003 \\
\hline$B T M$ & 0.029 & 0.739 & 0.029 & 0.745 \\
\hline INST.OWN & $-0.267 * *$ & 0.049 & $-0.321 * *$ & 0.050 \\
\hline EA.TWEETS & -0.031 & 0.348 & -0.010 & 0.794 \\
\hline$L E N G T H$ & -0.043 & 0.318 & 0.050 & 0.330 \\
\hline MEDIA.COVERAGE & 0.020 & 0.213 & 0.032 & 0.116 \\
\hline$N R A N K$ & $-0.025 *$ & 0.053 & -0.020 & 0.180 \\
\hline Lagged AB.SEARCH & $0.224 * * *$ & $<0.001$ & $0.272 * * *$ & $<0.001$ \\
\hline Past non-earnings-related visuals & & & 0.003 & 0.245 \\
\hline Fixed Effects & \multicolumn{2}{|c|}{ Firm, Year, Quarter } & \multicolumn{2}{|c|}{ Firm, Year, Quarter } \\
\hline Observations & \multicolumn{2}{|l|}{4,608} & \multicolumn{2}{|l|}{4,608} \\
\hline Adjusted-R $R^{2}$ & \multicolumn{2}{|l|}{$35.51 \%$} & \multicolumn{2}{|l|}{$40.55 \%$} \\
\hline
\end{tabular}

The table reports the results of estimating Eq. (2). Abnormal Google search volume for the firm's stock ticker for the earnings announcement day, AB.SEARCH, is regressed on the visuals indicator, VISUALS, and control variables. All variables are as defined in Appendix C. The regressions are estimated with firm, year, and quarter fixed effects. Standard errors are clustered by firm. ***, **, and * indicate statistical significance at the $1 \%, 5 \%$, and $10 \%$ levels, respectively (two-tailed tests)

The results in Table 4 indicate a positive relation between Google search volume and visuals. The coefficient on VISUALS is positive (0.068) and significant at the $p=0.062$ two-sided level. The magnitude of the coefficient indicates that an increase in VISUALS from 0 to 1 corresponds to an increase in $A B . S E A R C H$ by $27.3 \%$, relative to the average search volume on earnings announcement days $(0.068 / 0.249=27.3 \%)$. With respect to the control variables, the results suggest that investors pay greater attention to earning announcements of large firms (SIZE) and growth firms (GROWTH). The negative association between the Google search volume and the number of earnings announcements $(N R A N K)$ is consistent with investor distraction when more firms announce earnings on that day (Hirshleifer et al. 2009; Drake et al. 2012).

\subsection{Determinants of firms' choice to use visuals}

Before we complete the analyses for the visual attention hypothesis using returns as the attention outcome variable, it is helpful to examine the determinants of the use of visuals in an earnings tweet next. Firms use a range of presentation formats to disclose information to outsiders, including text, tables, and figures, as well as locations of 
different prominence within the document. Over the years, the array of formats has expanded beyond traditional financial statements and press releases to new formats such as PowerPoint presentations, podcasts, and visuals transmitted directly to the firm's followers. Firms' use of these formats is not universal. In fact, firms do not use visuals to disseminate earnings news in $76.7 \%$ of firm-quarter observations in our sample. This raises the question of what determines the choice to use visuals.

Several studies examine the determinants of firms' decision to present information more saliently by placing it in the headline or an earlier part of the document (e.g., Bowen, Davis, and Matsumoto 2005; Files, Swanson, and Tse 2009; Huang et al. 2018). The determinants examined in this research relate to firms' desire to emphasize information that makes the firm look better or that the management believes is more value relevant.

Building on this literature, we identify the determinants of firms' choice to use visuals. Since good earnings news and high sales growth portray the firm more favorably to outsiders than bad news and low sales growth, we expect that firms will be more likely to use visuals when earnings exceed market expectations and when sales growth is high. Regarding the value relevance of current performance, we examine how the choice of visuals relates to earnings persistence and sales growth persistence.

To examine whether firms have stronger incentives to attract attention with visuals when earnings news is good, we estimate the following logistic regression at the firmquarter level.

$$
\begin{aligned}
& \text { VISUALS }_{j t}= \alpha+\beta_{1} \text { POS.SURP }_{j t}+\beta_{2} \text { GROWTH }_{j t}+\beta_{3} \text { QUANT.ITEMS }_{j t} \\
&+\beta_{4} \text { WEB.LINKS }_{j t}+\beta_{5} \text { SIZE }_{j t}+\beta_{6} \text { ANA.FOLLOW }_{j t}+\beta_{7} \text { BTM }_{j t} \\
&+\beta_{8} \text { INST.OWN }_{j t}+\beta_{9} \text { FOLLOWERS }_{j t}+\beta_{10} \text { EA.TWEETS }_{j t} \\
&+\beta_{11} \text { LENGTH }_{j t}+\beta_{12} \text { NRANK }_{j t}+\beta_{13} \text { MEDIA.COVERAGE } \\
& j t \\
&+\{\text { Industry or Firm FE }\}+\text { Year FE }+ \text { Quarter FE }+\varepsilon_{j t} .
\end{aligned}
$$

If firms are more likely to use visuals when earnings news is good and when growth is high, we expect positive coefficients on the indicator of positive earnings surprise, POS.SURP, and sales growth, GROWTH.

The results are presented in Table 5. To examine the choice of visuals across firms within an industry, we estimate Eq. (3) with industry, year, and quarter fixed effects. Furthermore, to examine the choice of visuals over time within firms, we use firm, year, and quarter fixed effects. ${ }^{15}$ Consistent with the idea that managers use visuals to manage investor perceptions, we find some evidence that firms with good earnings news and high sales growth are more likely to use visuals. The marginal effects of POS.SURP (GROWTH) are positive in both regressions and significant in the regression with industry (firm) fixed effects. We do not find that analyst following, institutional ownership, or the number of same-day earnings announcements have a significant effect on firms' choice to use visuals.

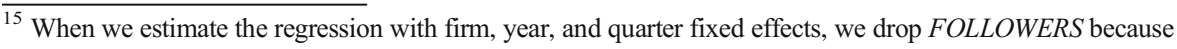
this variable does not vary within firms.
} 
Table 5 Firms' use of visuals

\begin{tabular}{|c|c|c|c|c|c|c|}
\hline & \multicolumn{3}{|c|}{$\begin{array}{l}\text { Across-Firm } \\
\text { Variation }\end{array}$} & \multicolumn{3}{|c|}{$\begin{array}{l}\text { Within- Firm } \\
\text { Variation }\end{array}$} \\
\hline & VISUALS & Marginal Effect & Z-stat & VISUALS & Marginal Effect & Z-stat \\
\hline POS.SURP & 0.248 & 0.028 & $2.44 * *$ & 0.182 & 0.019 & 1.03 \\
\hline GROWTH & 0.433 & 0.049 & $1.81^{*}$ & 1.266 & 0.132 & $2.78^{* * * *}$ \\
\hline QUANT.ITEMS & -0.468 & -0.053 & $-3.85^{* * *}$ & -0.961 & -0.100 & $-4.10^{* * * *}$ \\
\hline WEB.LINKS & -1.728 & -0.198 & $-9.67 * * *$ & -1.678 & -0.175 & $-4.66^{* * * *}$ \\
\hline SIZE & -0.118 & -0.014 & -1.85 & -1.453 & -0.152 & $-3.36^{* * *}$ \\
\hline ANA.FOLLOW & -0.046 & -0.005 & -0.35 & 0.512 & 0.053 & 1.05 \\
\hline BTM & 0.192 & 0.022 & 1.02 & -1.071 & -0.112 & -1.60 \\
\hline INST.OWN & 0.401 & 0.046 & 1.20 & 1.177 & 0.123 & 0.83 \\
\hline EA.TWEETS & 0.833 & 0.095 & $9.92 * * *$ & 2.369 & 0.247 & $10.40^{* * * *}$ \\
\hline LENGTH & 0.290 & 0.033 & $1.95^{*}$ & -0.026 & -0.003 & -0.09 \\
\hline$N R A N K$ & 0.012 & 0.001 & 0.27 & 0.055 & 0.006 & 0.58 \\
\hline MEDIA.COVERAGE & -0.032 & -0.004 & -0.66 & -0.096 & -0.010 & -0.88 \\
\hline FOLLOWERS & 0.376 & 0.043 & $9.70 * * *$ & & & \\
\hline Fixed Effects & \multicolumn{3}{|c|}{ Industry, Year, Quarter } & \multicolumn{3}{|c|}{ Firm, Year, Quarter } \\
\hline Observations & \multicolumn{3}{|c|}{4,719} & \multicolumn{3}{|c|}{2,277} \\
\hline Pseudo- $R^{2}$ & \multicolumn{3}{|l|}{$34.38 \%$} & \multicolumn{3}{|l|}{$48.63 \%$} \\
\hline
\end{tabular}

The table reports the results of estimating the logistic Eq. (3). The indicator of the firm's use of visuals in earnings-announcement-related tweets, VISUALS, is regressed on a set of predicted determinants. In the first three columns, the regression is estimated with industry, year, and quarter fixed effects. In the last three columns, the regression is estimated with firm, year, and quarter fixed effects. Standard errors are clustered by firm. All variables are as defined in Appendix C. ***, **, and * indicate statistical significance at the $1 \%, 5 \%$, and $10 \%$ levels, respectively (two-tailed tests)

The negative and significant marginal effects of QUANT.ITEMS and WEB.LINKS suggest that, on average, firms tend to use visuals as substitutes for quantitative items and web links. The results also show that firms that send many earnings-related tweets, EA.TWEETS, are more likely to use visuals. The positive coefficient on FOLLOWERS suggests that firms with more followers are more likely to use visuals.

We next examine the relation between the use of visuals and earnings persistence. This test is useful to distinguish between two alternative motives for the use of visuals: to inform or to disinform about future firm performance. Suppose that some investors use heuristics that are multiples of reported earnings to value the firm. If earnings shocks are persistent, making the new earnings salient will improve the informativeness of the earnings to the outside investors. However, if the earnings shocks are temporary, such as when there is temporary good news about earnings, making the earnings salient would lead to greater valuation errors by investors who use simple earnings multiples as a heuristic to value the firm.

In summary, if managers seek to opportunistically exploit temporary good earnings, they would choose to use visuals to increase the earnings salience when earnings persistence is low. Alternatively, if managers use visual salience to signal more persistent earnings, then visuals would be associated with higher earnings persistence. 
Several past studies have used persistence tests of firm financial performance to distinguish between informative versus opportunistic motives in the manager's choice of a presentation format. $\mathrm{Li}(2008)$ finds that managers opportunistically use low readability in annual reports when earnings are transitory or low. Huang, Teoh, and Zhang (2014) find that abnormal positive tone in earnings press releases is associated with low future performance. Huang et al. (2018) find that managers are more likely to use quantities in the earnings announcement headlines, which are considered more salient than other text, to attract attention to the firm when there is temporary good performance.

To test between the informative versus opportunistic incentive hypotheses, we estimate the following regressions of the association between visuals and earnings persistence.

$$
\begin{aligned}
& E A R N_{j t+1}=\alpha+\beta_{1} V I S . V A R_{j t} * E A R N_{j t}+\beta_{2} S_{I Z E_{j t}} * E A R N_{j t} \\
& +\beta_{3} \text { BTM }_{j t} * E A R N_{j t}+\beta_{4} S T D \cdot E A R N_{j t} * E A R N_{j t} \\
& +\beta_{5} \operatorname{LOSS}_{j t}{ }^{E} E A R N_{j t}+\beta_{6} E A R N_{j t}+\beta_{7} E A R N_{j t-3}+\beta_{8} V I S . V A R_{j t} \\
& +\beta_{9} S I Z E_{j t}+\beta_{10} \text { BTM }_{j t}+\beta_{11} S T D \cdot E A R N_{j t}+\beta_{12} L_{O S S} \\
& + \text { Firm FE }+ \text { Year FE }+ \text { Quarter FE }+\varepsilon_{j t} \text {, }
\end{aligned}
$$

where VIS.VAR is either the visuals indicator, VISUALS, or the residuals from the firststage OLS regression (3) with industry, year, and quarter fixed effects, VISUALS.RES. We use VISUALS.RES to control for the determinants of visuals used in the first stage. The interaction of VIS.VAR and EARN ${ }_{t}$ captures the effect of VIS.VAR on the earnings persistence. In addition to size and book-to-market, we control for earnings volatility, STD.EARN, and the indicator of losses, LOSS, since volatile earnings and negative earnings are less persistent (e.g., Hayn 1995; Dichev and Tang 2009). We also include earnings for the same quarter last year, $E A R N_{t-3}$, to control for seasonality. If firms use visuals when earnings are more (less) persistent, the coefficient on the interaction between visuals and earnings should be positive (negative).

Investors who use heuristics to value the firm sometimes also consider the sales growth multiple instead of the earnings multiple. Therefore, we also examine the relation between visuals and persistence of sales growth, using the following regressions.

$$
\begin{aligned}
& G R O W T H_{j t+1}=\alpha+\beta_{1} V_{I S . V A R}{ }^{*} G R O W T H_{j t}+\beta_{2} S_{I Z E_{j t}} * G R O W T H_{j t} \\
& +\beta_{3} \text { BTM }_{j t} * G R O W T H_{j t}+\beta_{4} \text { STD.GROWTH } H_{j t} * G R O W T H_{j t} \\
& +\beta_{5} \text { NEG.GROWTH }_{j t} * G R O W T H_{j t}+\beta_{6} \text { GROWTH }_{j t} \\
& +\beta_{7} \text { GROWTH }_{j t-3}+\beta_{8} V_{I S . V A R}{ }_{j t}+\beta_{9} S I Z E_{j t}+\beta_{10} \text { BTM }_{j t} \\
& +\beta_{11} \text { STD.GROWTH }{ }_{j t}+\beta_{12} \text { NEG.GROWTH }{ }_{j t}+\text { Firm FE }^{2} \\
& + \text { Year FE }+ \text { Quarter FE }+\varepsilon_{j t},
\end{aligned}
$$


where we include controls for the volatility of sales growth, STD.GROWTH, and the indicator of negative sales growth, NEG.GROWTH, since we expect volatile growth and negative growth to be less persistent. Similar to Eq. (4a), we also include sales growth for the same quarter last year, $\mathrm{GROWTH}_{t-3}$, to control for seasonality.

Table 6 presents the results. Panel A shows the results from estimating the earnings persistence Eq. (4a) in the full sample. In Panel B, we estimate the earning persistence equation excluding loss firms to control for the possibility that firms use Twitter to manage crises (Lee, Hutton, and Shu 2015). The results show that both VISUALS*EARN and VISUALS.RES*EARN are negative and significant both in the full sample and the sample that excludes loss firms. The results suggest that, rather than use visuals to signal more persistent earnings, firms use them when earnings are less persistent. This result provides support, using a very different type of data, for the Huang et al. (2018) conclusion that managers use more salient disclosure to attract attention to temporary good earnings news, consistent with managers trying to "make hay while the sun shines." The Huang et al. (2018) tests measure salience by the use of quantitative information in the announcement headline, whereas our test measures attention by the use of visuals on Twitter. The results of estimating Eq. (4b) show a similar negative relation between the use of visuals and the persistence of sales growth (Table 6 Panel C). The coefficients on VISUALS*GROWTH and VISUALS.RES*GROWTH are negative and significant.

\subsection{Visuals and market reactions to earnings news}

We now return to the second set of consequence tests for the visual attention hypothesis. We examine the relation between visuals and investor reaction to earnings news at the announcement date and in the post-announcement window. The direction of visual-return associations may provide insight on whether the SEC's encouragement of the use of visuals to announce earnings news leads to more efficient pricing of the earnings news, and whether the managers' incentive for choosing to use visuals is to inform investors. Alternatively, the visual-return associations may show that the visuals cause investors to misvalue the earnings news, and that managers' incentive in choosing to use visuals is opportunistic.

Drawing from limited attention theory, our visual attention hypothesis predicts that making news more salient by using visuals in earnings tweets results in a stronger immediate price reaction and either a smaller drift in the same direction or a stronger post-announcement reversal (Hirshleifer and Teoh 2003; Hirshleifer, Lim, and Teoh 2011). Our findings in Table 3 suggest that visuals increase the salience of earnings news. Thus, the visual attention hypothesis has a two-part prediction: First, it predicts a higher return response, in the announcement window, to the earnings news when firms use visuals to disseminate that news. ${ }^{16}$ Second, the visual attention hypothesis predicts a lower post-announcement window return response to earnings news when firms use visuals to disseminate that news.

To test for the immediate reaction to earnings news, we estimate the following regressions of cumulative abnormal return around earnings announcements, $C A R(-1,+$ 1), at the firm-quarter level.

\footnotetext{
${ }^{16}$ We do not have an exogenous shock for visuals in the regression design to permit us to make a definitive causal inference that visuals increase investor attention to the earnings news, resulting in a larger ERC. However, visuals are associated with a lower earnings persistence, which would suggest that endogeneity of visuals would, if anything, bias against our finding a larger ERC for visuals.
} 
Table 6 Earnings persistence and sales growth persistence

\begin{tabular}{|c|c|c|c|c|}
\hline & \multicolumn{2}{|c|}{$V I S . V A R=V I S U A L S$} & \multicolumn{2}{|c|}{$V I S . V A R=V I S U A L S . R E S$} \\
\hline & $E A R N_{t+1}$ & $p$ value & $E A R N_{t+1}$ & $p$ value \\
\hline \multicolumn{5}{|c|}{ Panel A: Earnings Persistence—All Firms } \\
\hline$V I S . V A R^{*} E A R N_{t}$ & $-0.179 * * *$ & $<0.001$ & $-0.146^{* * *}$ & $<0.001$ \\
\hline$S I Z E^{*} E A R N_{t}$ & 0.002 & 0.856 & -0.006 & 0.533 \\
\hline$B T M^{*} E A R N_{t}$ & 0.001 & 0.981 & 0.011 & 0.822 \\
\hline$S T D \cdot E A R N^{*} E A R N_{t}$ & 0.366 & 0.489 & 0.361 & 0.497 \\
\hline$L O S S^{*} E A R N_{t}$ & 0.017 & 0.737 & 0.009 & 0.853 \\
\hline$E A R N_{t}$ & 0.136 & 0.165 & $0.164 *$ & 0.099 \\
\hline$E A R N_{t-3}$ & $0.139 * * *$ & $<0.001$ & $0.140 * * *$ & $<0.001$ \\
\hline VIS.VAR & $0.002 * *$ & 0.014 & 0.001 & 0.189 \\
\hline SIZE & $0.003 * * *$ & 0.007 & $0.003 * *$ & 0.018 \\
\hline BTM & $-0.018 * * *$ & $<0.001$ & $-0.019 * * *$ & $<0.001$ \\
\hline STD.EARN & $-0.093 * * *$ & 0.001 & $-0.091 * * *$ & 0.001 \\
\hline LOSS & 0.001 & 0.213 & 0.001 & 0.358 \\
\hline Fixed Effects & \multicolumn{2}{|c|}{ Firm, Year, Quarter } & \multicolumn{2}{|c|}{ Firm, Year, Quarter } \\
\hline Observations & \multicolumn{2}{|c|}{4,612} & \multicolumn{2}{|c|}{4,612} \\
\hline Adjusted $R^{2}$ & \multicolumn{2}{|l|}{$49.52 \%$} & \multicolumn{2}{|l|}{$49.79 \%$} \\
\hline \multicolumn{5}{|c|}{ Panel B: Earnings Persistence_Excluding Loss Firms } \\
\hline$V I S . V A R * E A R N_{t}$ & $-0.100 * *$ & 0.015 & $-0.096 * *$ & 0.025 \\
\hline$S I Z E^{*} E A R N_{t}$ & -0.003 & 0.809 & -0.009 & 0.514 \\
\hline$B T M^{*} E A R N_{t}$ & $-0.279 * * *$ & 0.002 & $-0.281 * * *$ & 0.003 \\
\hline$S T D \cdot E A R N^{*} E A R N_{t}$ & $-2.344 * *$ & 0.011 & $-2.366^{* *}$ & 0.011 \\
\hline$L O S S^{*} E A R N_{t}$ & $0.294 * *$ & 0.031 & $0.329 * *$ & 0.018 \\
\hline$E A R N_{t}$ & $0.149 * * *$ & $<0.001$ & $0.149 * * *$ & $<0.001$ \\
\hline$E A R N_{t-3}$ & 0.001 & 0.202 & 0.001 & 0.392 \\
\hline VIS.VAR & $0.003^{* *}$ & 0.022 & $0.003 * *$ & 0.021 \\
\hline SIZE & $-0.012 * * *$ & $<0.001$ & $-0.012 * * *$ & $<0.001$ \\
\hline$B T M$ & $-0.014 * * *$ & 0.733 & $-0.014 * * *$ & 0.730 \\
\hline STD.EARN & $-0.100 * *$ & 0.015 & $-0.096^{* *}$ & 0.025 \\
\hline LOSS & -0.003 & 0.809 & -0.009 & 0.514 \\
\hline Fixed Effects & \multicolumn{2}{|c|}{ Firm, Year, Quarter } & \multicolumn{2}{|c|}{ Firm, Year, Quarter } \\
\hline Observations & \multicolumn{2}{|l|}{4,006} & \multicolumn{2}{|l|}{4,006} \\
\hline Adjusted $R^{2}$ & \multicolumn{2}{|l|}{$48.94 \%$} & \multicolumn{2}{|l|}{$49.00 \%$} \\
\hline \multicolumn{5}{|c|}{ Panel C: Persistence of Sales Growth } \\
\hline VIS.VAR*GROWTH & $-0.168 * * *$ & $<0.001$ & $-0.174 * * *$ & $<0.001$ \\
\hline$S I Z E^{*} G R O W T H_{t}$ & $-0.016^{*}$ & 0.065 & $-0.028 * * *$ & 0.001 \\
\hline$B T M^{*} G R O W T H_{t}$ & $-0.183 * * *$ & $<0.001$ & $-0.192 * * *$ & $<0.001$ \\
\hline STD.GROWTH*GROWTH $H_{t}$ & 0.026 & 0.316 & 0.017 & 0.497 \\
\hline NEG.GROWTH*GROWTH $H_{t}$ & 0.034 & 0.338 & $0.074 * *$ & 0.045 \\
\hline $\mathrm{GROWTH}_{t}$ & $0.831 * * *$ & $<0.001$ & $0.900 * * *$ & $<0.001$ \\
\hline$G R O W T H_{t-3}$ & $-0.263 * * *$ & $<0.001$ & $-0.266^{* * *}$ & $<0.001$ \\
\hline VIS.VAR & 0.010 & 0.206 & $0.014 *$ & 0.073 \\
\hline SIZE & $0.047 * * *$ & $<0.001$ & $0.051 * * *$ & $<0.001$ \\
\hline
\end{tabular}


Table 6 (continued)

\begin{tabular}{|c|c|c|c|c|}
\hline & \multicolumn{2}{|c|}{ VIS. VAR $=$ VISUALS } & \multicolumn{2}{|c|}{ VIS. VAR $=$ VISUALS.RES } \\
\hline & $E A R N_{t+1}$ & $p$ value & $E A R N_{t+1}$ & $p$ value \\
\hline BTM & $-0.064 * * *$ & 0.001 & $-0.061 * * *$ & 0.003 \\
\hline STD.GROWTH & 0.027 & 0.380 & $0.054 *$ & 0.091 \\
\hline NEG.GROWTH & -0.010 & 0.141 & -0.008 & 0.220 \\
\hline Fixed Effects & \multicolumn{2}{|c|}{ Firm, Year, Quarter } & \multicolumn{2}{|c|}{ Firm, Year, Quarter } \\
\hline Observations & \multicolumn{2}{|c|}{4,600} & \multicolumn{2}{|c|}{4,600} \\
\hline Adjusted $R^{2}$ & \multicolumn{2}{|l|}{$57.25 \%$} & \multicolumn{2}{|l|}{$56.12 \%$} \\
\hline
\end{tabular}

The table reports the results of estimating Eqs. (4a) and (4b), where the dependent variable $E A R N_{t+1}$ is earnings for quarter $t+1$. In the first two columns, the visual variable, VIS.VAR, is the indicator of the firm's use of visuals in earnings-announcement-related tweets, VISUALS. In the last two columns, the visual variable, VIS.VAR, is residual visuals, VISUALS.RES, calculated as the residuals from the first-stage regression (3). All other variables are as defined in Appendix C. The regressions are estimated with firm, year, and quarter fixed effects. Standard errors are clustered by firm. $* * *, * *$, and $*$ indicate statistical significance at the $1 \%, 5 \%$, and $10 \%$ levels, respectively (two-tailed tests)

$$
\begin{aligned}
C A R(-1,+1)_{j t}= & \alpha+\beta_{1} \text { VIS.VAR }_{j t} * R S U E_{j t}+\beta_{2} \text { QUANT.ITEMS }_{j t} * R S U E_{j t} \\
& +\beta_{3} \text { WEB.LINKS }_{j t} * R S U E_{j t}+\beta_{4} \text { SIZE }_{j t} * R S U E_{j t} \\
& +\beta_{5} \text { ANA.FOLLOW }_{j t} * R S U E_{j t}+\beta_{6} \text { GROWTH }_{j t} * R S U E_{j t} \\
& +\beta_{7} \text { BTM }_{j t} * R S U E_{j t}+\beta_{8} \text { INST.OWN }_{j t} * R S U E_{j t} \\
& +\beta_{9} \text { EA.TWEETS }_{j t} * R S U E_{j t}+\beta_{10} \text { LENGTH }_{j t} * R S U E_{j t} \\
& +\beta_{11} \text { MEDIA.COVERAGE }_{j t} * R S U E_{j t}+\beta_{12} \text { RSUE }_{j t} \\
& + \text { Main Effects }_{j t}+\text { Firm FE }+ \text { Year FE }_{\text {Fin }} \text { Quarter FE }_{+} \varepsilon_{j t},(5 \mathrm{a})
\end{aligned}
$$

where VIS.VAR is either the visuals indicator, VISUALS, or residuals visuals, VISUALS.RES. The benefit of using residual visuals is that it controls for the predicted determinants of firms' choice of visuals. If visuals positively influence the response to earnings news, then we expect a positive coefficient on the interaction between visuals and earnings surprise $\left(\beta_{1}>0\right){ }^{17}$

The results are presented in Table 7 Panel A. The coefficients on both VISUALS*RSUE and VISUALS.RES*RSUE are positive and significant. The results are consistent with the prediction that investor response to earnings news is stronger when firms use visuals to disseminate that news. Both RSUE and VISUALS range from 0 to 1 , so an increase in VISUALS from 0 to 1 corresponds to an increase in the differential CAR between the top and bottom deciles of $2.0 \%(0.020)$. The average ERC, estimated from a regression of $C A R(-1,+1)$ on $R S U E$ and commonly used controls for size and book-to-market, is 0.080 (untabulated). Compared to the average

\footnotetext{
${ }^{17}$ We do not include RETWEETS and AB.SEARCH since we view them as outcomes of visual attention (See Eqs. (1) and (2)). The results are similar when we include these variables and their interactions with earnings surprise (untabulated).
} 


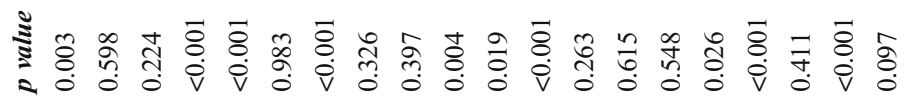

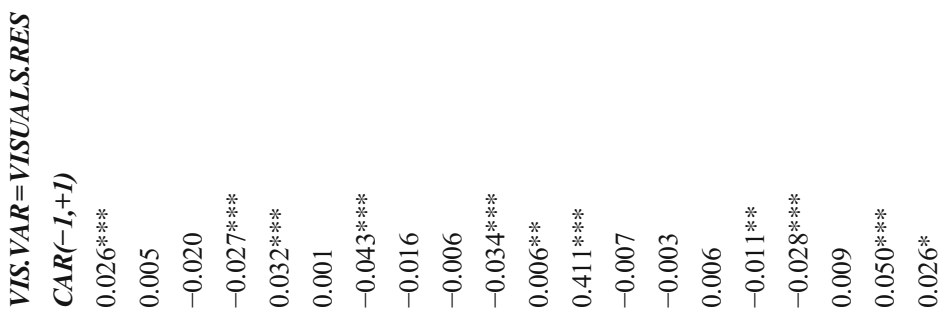

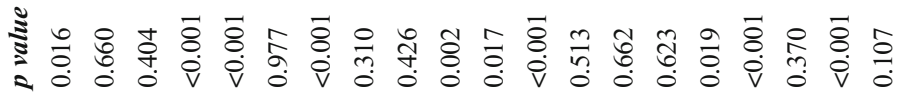

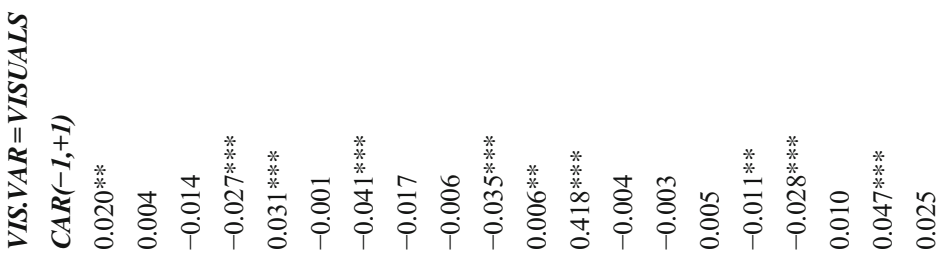




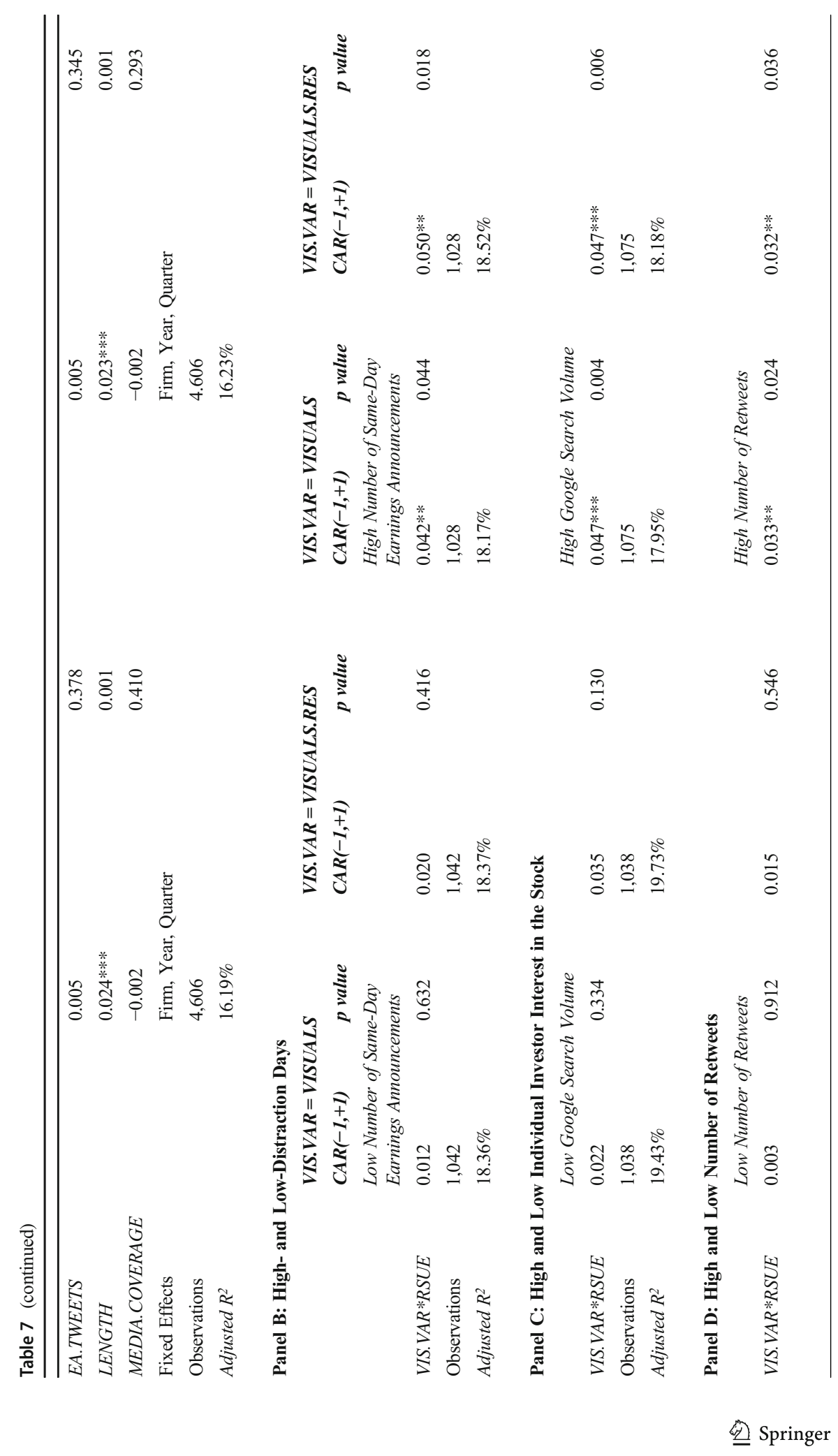




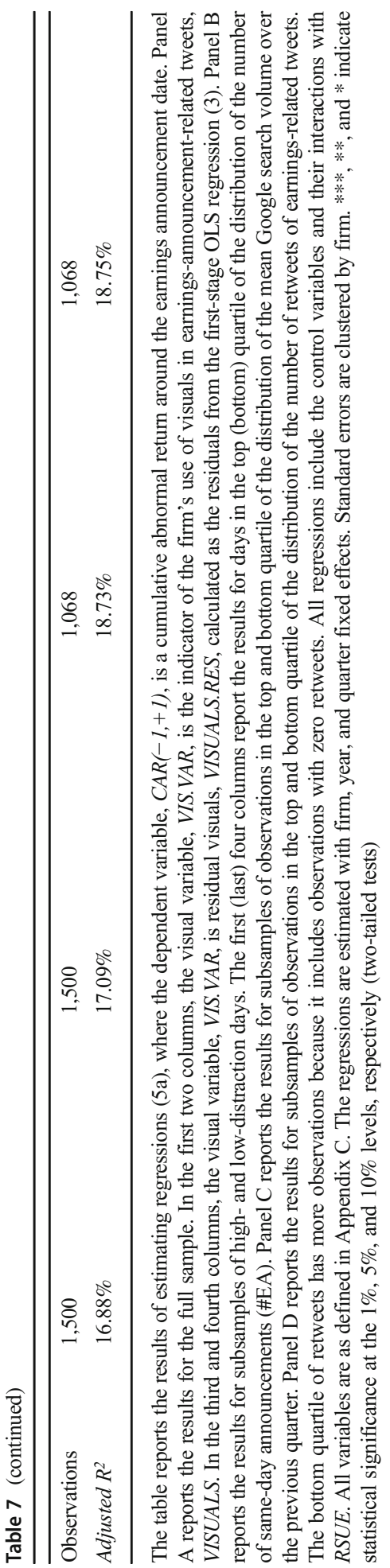


ERC, visuals are associated with an economically large increase in immediate investor reaction by one-quarter $(0.020 / 0.080=25 \%)$.

We examine several additional cross-sectional tests of the market reaction to visual salience. Visual salience is likely to be most important when investors face a high information load. Because attention is finite, it must be allocated selectively. When investors have to process many information signals, their attention to each signal suffers. In the context of earnings announcements, past research has found that investors are distracted by many same-day earnings announcements by other firms (Hirshleifer et al. 2009). At such times, visuals can make a firm's announcement stand out, leading to a stronger reaction to its earnings news. Thus we expect the association between visuals and ERC to be more pronounced on days when the firm is competing with many other firms for scarce investor attention.

Visual salience is also likely to matter more for stocks that are of greater interest to individual investors, who are likely to be more heavily influenced by the form of disclosure presentation, relative to institutional investors (e.g., Lawrence 2013). To capture individual investor interest in the stock, we use recent Google search volume for the stock, because research suggests that Google search reflects information acquisition by individual investors (Da et al. 2011). Specifically, we use the mean Google search volume (SVI) for the stock over the previous quarter.

Finally, not all visuals attract the same level of attention. In our non-market-based tests in 4.2, we use retweets to gauge attention and find significant variation in the number of times earnings-related tweets are retweeted. When visuals result in more (fewer) retweets of earnings-related tweets, we expect a stronger (weaker) association with returns. Thus we examine whether the association between visuals and ERC is more pronounced when the number of retweets of earnings-related tweets is high.

We rank sample observations based on the above factors and allocate observations in the top (bottom) quartile of the distribution into high (low) subsamples of investor attention. We then estimate the investor reaction model (5a) separately within the high and low subsamples and report the coefficient on the interactive term VIS.VAR*RSUE.

Table 7 Panels B, C, and D present the results for distraction days, individual investor interest in the stock, and the number of retweets, respectively. Consistent with our expectations, the results show that the positive association between visuals and ERC is more pronounced on days when investors face many competing announcements; for firms with high individual investor interest; and for announcements with many retweets of earningsrelated tweets. The coefficients on both VISUALS*RSUE and VISUALS.RES*RSUE are positive and significant in each of the three high subsamples. Except for the marginally significant coefficient on VISUALS.RES*RSUE in the low Google search subsample, the coefficient on the interaction term is insignificant in the other two low subsamples.

Next, we examine the post-announcement return reaction. If higher visual attention leads to a stronger immediate reaction to earnings news, we expect a lower underreaction and therefore a less positive or more negative post-announcement reaction. Past research has found that long-window abnormal returns measures are noisy and that a disproportionate fraction of the post-announcement reaction is concentrated in the short-window around the next earnings announcement (Bernard and Thomas 1990). Therefore, we use a three-day window around the next earnings announcement to increase the test power to detect the post-announcement reaction. Specifically, we estimate the following regressions of cumulative abnormal return around next-quarter 
earnings announcements, $C A R(-1,+1)_{\text {NEXT.QTR }}$, at the firm-quarter level.

$$
\begin{aligned}
& C A R(-1,+1)_{N E X T . Q T R, j t}=\alpha+\beta_{1} V I S . V A R_{j t} * R S U E_{j t} \\
& +\beta_{2} \text { QUANT.ITEMS } \text { jt } * R S U E_{j t} \\
& +\beta_{3} \text { WEB.LINKS } S_{j t} * R S U E_{j t}+\beta_{4} \operatorname{SIZE}_{j t} * R S U E_{j t} \\
& +\beta_{5} \text { ANA.FOLLOW }{ }_{j t} * R S U E_{j t} \\
& +\beta_{6} \text { GROWTH }_{j t} * R S U E_{j t}+\beta_{7} B T M_{j t} * R S U E_{j t} \\
& +\beta_{8} I N S T . O W N_{j t} * R S U E_{j t} \\
& +\beta_{9} \text { EA.TWEETS }_{j t} * R S U E_{j t} \\
& +\beta_{10} L_{E N G T H} * R S U E_{j t} \\
& +\beta_{11} \text { MEDIA.COVERAGE } E_{j t} * R S U E_{j t}+\beta_{12} R S U E_{j t} \\
& + \text { Main Effects }{ }_{j t}+\text { Firm FE }+ \text { Year FE } \\
& + \text { Quarter FE }+\varepsilon_{j t} \text {. }
\end{aligned}
$$

If visuals attract investor attention and result in a stronger immediate reaction, then we expect the association between earnings news and returns around the next earnings announcement to be lower when firms use visuals. That is, the coefficient on the interaction of earnings news and visuals should be negative $\left(\beta_{1}<0\right)$.

The results are presented in Table 8 . Consistent with our prediction, we find some evidence that the post-announcement reaction to earnings news is lower when visuals are used to disseminate earnings news. The coefficients on both VISUALS*RSUE and VISUALS.RES*RSUE are negative and significant at the $p=0.066$ and 0.046 two-sided levels, respectively. When we keep all other variables constant and equal to their sample means, an increase in VISUALS from 0 to 1 corresponds to a decrease in CAR $(-1,+1)_{\text {NEXT.QTR }}$ between the top and bottom deciles of $1.9 \%(0.019)$. The $1.9 \%$ decrease is almost as large as the $2.0 \%$ increase in the initial reaction in Table 7 Panel A. Thus it appears that investors largely undo their initial reaction due to visuals.

The evidence of a return reversal suggests that investors overreact to earnings announcements with visuals. When this finding is coupled with the finding of lower earnings persistence in firms that disseminate earnings news using visuals, the joint evidence suggests that visuals do not improve investors' comprehension of financial statements and could be deployed opportunistically by managers. Visuals, therefore, are a doubleedged sword. ${ }^{18}$ They can help increase investor engagement with financial disclosures (as desired by the SEC in its Plain Writing Initiative), but they can also reduce the informational efficiency of the capital markets because of managerial agency incentives.

\footnotetext{
${ }^{18}$ Statistics, graphs, and charts can be very helpful in aiding understanding of data, but they can also be deployed to lie about the data. See Darren Huff's $(1954,1991)$ famous book How to Lie with Statistics, and the "Lie Factor" in Edward Tufte's (2001) book The Visual Display of Quantitative Information. See Beattie and Jones (2008) for examples of impression management through selectivity and distortion of graphs in accounting.
} 
Table 8 Returns around the next earnings announcement

\begin{tabular}{|c|c|c|c|c|}
\hline & \multicolumn{2}{|l|}{$V I S . V A R=V I S U A L S$} & \multicolumn{2}{|c|}{$V I S . V A R=V I S U A L S . R E S$} \\
\hline & $C A R(-1,+1)_{N E X T . Q T R}$ & $p$ value & $C A R(-1,+1)_{\text {NEXT.QTR }}$ & $p$ value \\
\hline VIS.VAR*RSUE & $-0.019 *$ & 0.066 & $-0.021 * *$ & 0.046 \\
\hline QUANT.ITEMS*RSUE & 0.011 & 0.281 & 0.009 & 0.358 \\
\hline WEB.LINKS*RSUE & -0.006 & 0.760 & 0.0002 & 0.992 \\
\hline$S I Z E^{*} R S U E$ & $0.012^{* * * *}$ & 0.001 & $0.011 * * *$ & 0.002 \\
\hline ANA.FOLLOW*RSUE & $-0.018 * *$ & 0.020 & $-0.018^{* *}$ & 0.023 \\
\hline GROWTH*RSUE & $0.037 * *$ & 0.041 & $0.036^{* *}$ & 0.045 \\
\hline$B T M^{*} R S U E$ & $0.029 * *$ & 0.011 & $0.030 * * *$ & 0.010 \\
\hline INST.OWN*RSUE & 0.017 & 0.351 & -0.015 & 0.409 \\
\hline EA.TWEETS*RSUE & $0.014 *$ & 0.075 & $0.015^{*}$ & 0.066 \\
\hline$L E N G T H * R S U E$ & -0.018 & 0.148 & -0.018 & 0.147 \\
\hline MEDIA.COVERAGE*RSUE & $-0.008 * * *$ & 0.006 & $-0.008 * * *$ & 0.008 \\
\hline$R S U E$ & -0.008 & 0.898 & -0.008 & 0.902 \\
\hline VIS.VAR & 0.008 & 0.219 & 0.010 & 0.161 \\
\hline QUANT.ITEMS & -0.001 & 0.931 & 0.001 & 0.964 \\
\hline WEB.LINKS & 0.010 & 0.387 & 0.007 & 0.522 \\
\hline$S I Z E$ & $-0.048 * * *$ & $<0.001$ & $-0.048 * * *$ & $<0.001$ \\
\hline ANA.FOLLOW & -0.009 & 0.254 & -0.009 & 0.243 \\
\hline GROWTH & -0.015 & 0.217 & -0.015 & 0.226 \\
\hline BTM & $-0.022^{*}$ & 0.051 & $-0.023 * *$ & 0.045 \\
\hline INST.OWN & -0.025 & 0.145 & -0.024 & 0.166 \\
\hline EA.TWEETS & $-0.020 * * *$ & $<0.001$ & $-0.021 * * *$ & $<0.001$ \\
\hline LENGTH & 0.010 & 0.245 & 0.010 & 0.244 \\
\hline MEDIA.COVERAGE & 0.003 & 0.256 & 0.002 & 0.278 \\
\hline Fixed Effects & \multicolumn{2}{|c|}{ Firm, Year, Quarter } & \multicolumn{2}{|c|}{ Firm, Year, Quarter } \\
\hline Observations & 4,619 & & 4,619 & \\
\hline Adjusted $R^{2}$ & $6.51 \%$ & & $6.52 \%$ & \\
\hline
\end{tabular}

The table reports the results of estimating regressions $(5 \mathrm{~b})$, where the dependent variable, CAR $(-1,+1)_{\text {NEXT.QTR }}$, is a cumulative abnormal return around the next-quarter earnings announcement date. The visual variable, VIS.VAR, in the first two columns is the indicator of the firm's use of visuals in earningsannouncement-related tweets, VISUALS, and in the last two columns is residual visuals, VISUALS.RES, calculated as the residuals from the first-stage OLS regression (3). All other variables are as defined in Appendix C. The regressions are estimated with firm, year, and quarter fixed effects. Standard errors are clustered by firm. $* * *, * *$, and $*$ indicate statistical significance at the $1 \%, 5 \%$, and $10 \%$ levels, respectively (two-tailed tests)

\section{Robustness tests and additional analyses}

\subsection{Instrumental variable approach}

We use an instrumental variable approach to further mitigate the concern that the choice of visuals may be influenced by omitted correlated variables. As an instrument 
for VISUALS, we use the firm propensity to use visuals in tweets unrelated to earnings in the week prior to the earnings announcement date. The measure is a reasonable instrument, because past use of non-earnings-related visuals is unlikely to be driven by the firm's desire to attract investor attention to the earnings announcement yet likely to predict the firm's use of visuals in earnings-related tweets on the earnings announcement day. The direct attention effect of past non-earnings-related visuals, if any, is likely short-lived, so they should not directly affect attention to the future earnings announcement. Since the instrument reflects the ex ante propensity to use visuals, it helps mitigate the endogeneity concern that firms use visuals in response to higher announcement returns.

Before we describe the results for the IV analysis, we first test our assumption that the attention to visuals in non-earnings tweets in the period preceding the earnings announcement is short-lived and therefore unlikely to raise investor attention to the earnings announcement directly in Table 4. We add the past non-earnings-related visuals variable to the regression, in Table 4, of visuals on the abnormal Google search volume proxy for investor attention. Table 4 results confirm that the past visuals variable is unrelated to abnormal Google search volume, whereas the VISUALS variable remains robust.

Turning to the results of the IV analysis in Table 9, the instrument for VISUALS is Past non-earnings-related visuals and the instrument for VISUALS*RSUE is the interactive variable Past non-earnings-related visuals*RSUE. Panel A shows the results of the first-stage estimation, where VISUALS and VISUALS*RSUE are regressed on their instruments and control variables. Consistent with a firm's past non-earningsrelated visuals predicting the firm's tendency to use visuals in earnings-related tweets on the earnings announcement date, VISUALS and VISUALS*RSUE are significantly associated with their instruments. The (weak) under-identification test reported at the bottom of Panel A rejects the null that there is no correlation (only a weak correlation) between the instrument and the endogenous variable $(p<0.001)$.

Panel B reports the results of the second-stage estimation of the market reaction tests, where we use the predicted values from the first-stage estimation. The results are consistent with the findings in Tables 7 and 8. The coefficient on the instrumented VISUAL *RSUE is positive and significant in the regression of the immediate market reaction and negative and significant in the regression of the market reaction around the next earnings announcement. The significant statistic for the endogeneity test reported in the bottom row of Panel B indicates that the two-stage instrumental variable approach corrects a significant amount of the endogeneity present in the ordinary least squares estimation.

\subsection{Alternative measures of user engagement}

We conduct robustness tests of our results to alternative measures of user engagement. First, we use two alternative continuous measures of retweets: \#RETWEETS is the number of retweets for earnings-announcement tweets, and LOG.RETWEETS is the natural logarithm of one plus the number of retweets for earnings-announcements tweets. RETWEETS tweet.level $_{\text {and } \# R E T W E E T S}$ tweet.level are similar variables at the individual tweet level. 


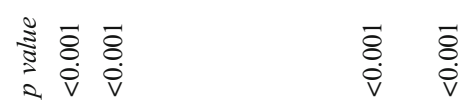

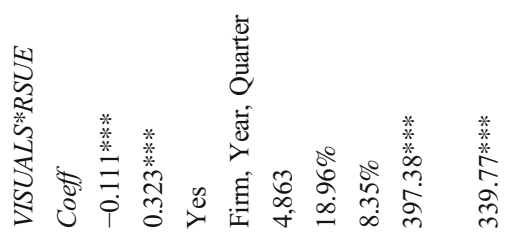

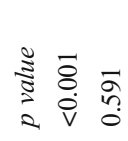

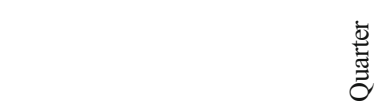

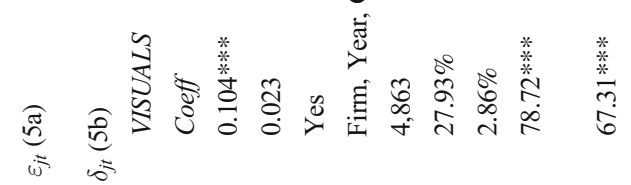

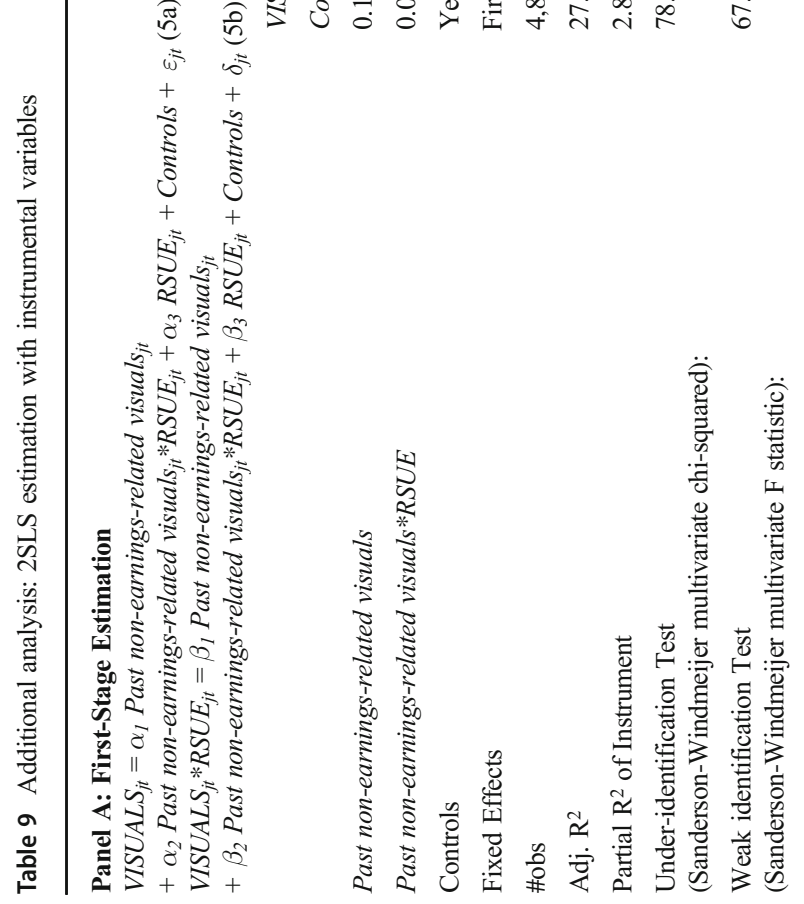

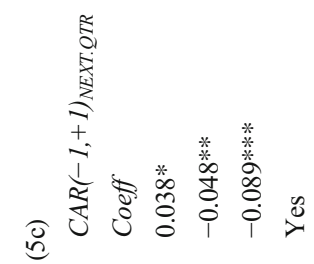

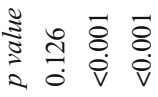

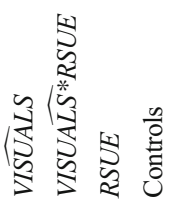




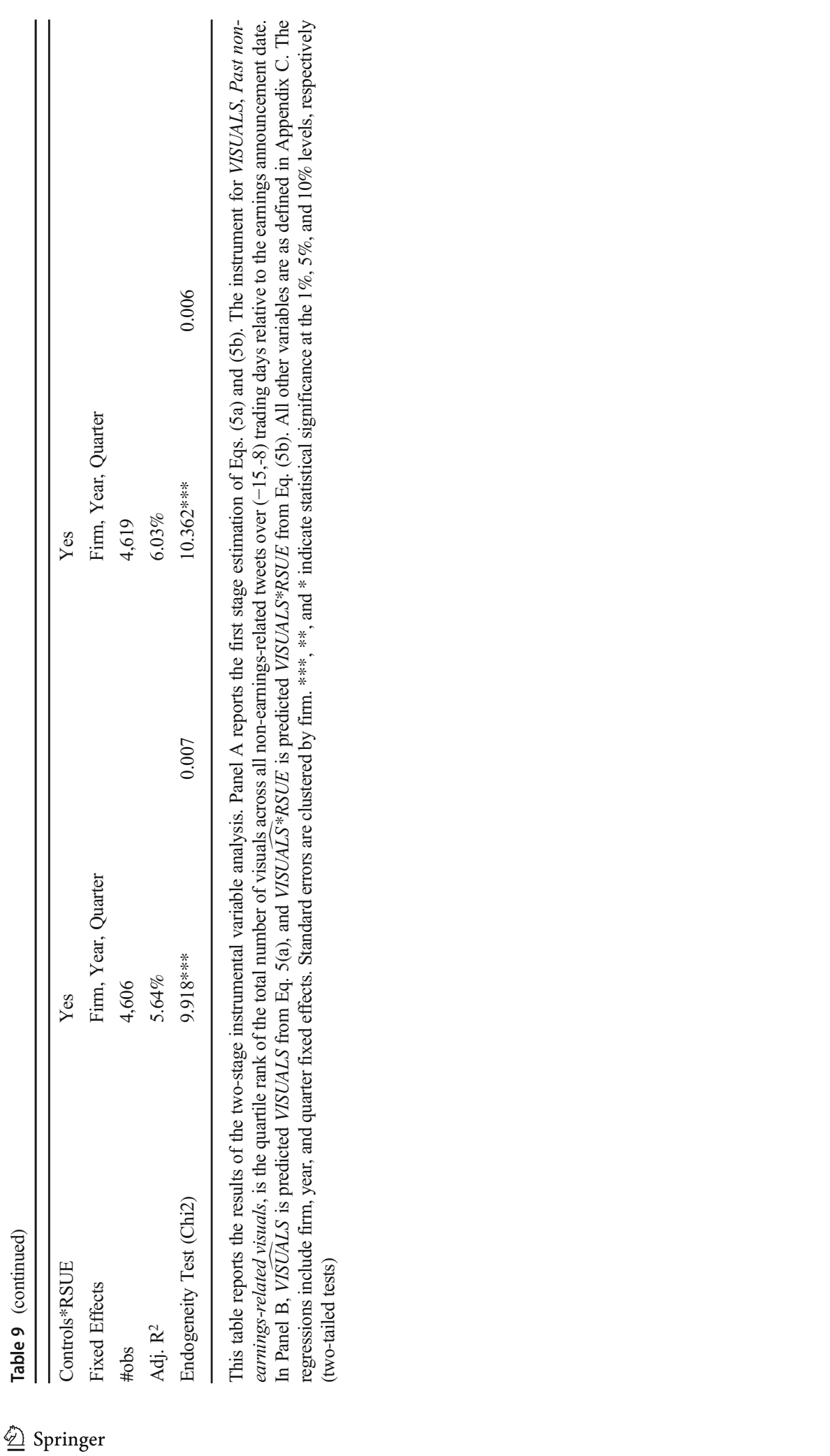


Second, twitter users can also reveal their engagement with a tweet by "liking" it, so we examine two other user engagement measures, which combine retweets and likes. COMBINED1 is an indicator that equals one if at least one earnings-announcement tweet was retweeted or liked, and zero otherwise. COMBINED2 is the natural logarithm of one plus the number of retweets plus the number of likes for earningsannouncements tweets. COMBINED $1_{\text {tweet.level }}$ and COMBINED $2_{\text {tweet.level }}$ are similar measures of retweets and likes at the individual tweet level. Consistent with the results from Table 3, untabulated results show that the association between visuals and user engagement with earnings-announcement tweets is positive and significant for all of these alternative measures of user engagement.

\subsection{Visual format versus new information}

Greater engagement with visual tweets may be driven by new information contained in visuals rather than by the visual format itself. To investigate this issue, we consider instances of earnings-announcement tweets with uninformative visuals. (See the third example in Appendix A for examples of uninformative visuals.) Specifically, we examine visuals with no text or with text that is similar to the text part of the tweet. We consider visuals as being least likely to contain new information when they contain no text or when they are ranked in the top quartile of the cosine text similarity measure. Untabulated results show that the effect of visuals on retweets and ERC remains positive and significant when we restrict the analysis to uninformative visuals. Thus our earlier results that visuals increase user engagement are not driven solely by new information contained in visuals.

\subsection{Resource availability}

Firms with more resources may be more able to use visuals. We find that more than $95 \%$ of our firms use visuals at least once in non-earnings-related tweets. So it seems unlikely that a resource constraint is preventing a firm from producing visuals for use in an earnings-related tweet. Nevertheless, for a more stringent test that removes the resource availability factor for the choice of visuals, we remove firm-quarter observations in any quarter before the first use of visuals in any tweet, whether the tweet is earnings or non-earnings announcement related. This sample effectively removes firms where producing visuals could be hindered by a resource or technological constraint. We find that the ERC and PEAD results in Tables 7 and 8 are robust to using this sample, with very little change in the estimated coefficients (untabulated).

\subsection{Higher awareness versus greater dissemination}

Visuals may increase the market reaction to earnings news both by raising awareness of the earnings news and by increasing its dissemination as a result of the retweets. In general, higher-awareness and greater-reach channels are likely to operate, but one may be more important than the other. Peress (2014) and Blankespoor, deHaan, and Zhu (2018) find that wider dissemination of news increases trading volume and liquidity. To compare the two channels, we add the interaction term RETWEETS*RSUE to the 
regression of Eq. (5a) in Table 7 Panel A. Untabulated results show that RETWEETS*RSUE is not statistically significant, whereas VISUALS*RSUE remains significantly positive. In other words, retweets by themselves increase reach but do not increase the attention of those reached as much as visuals in the tweets do.

\section{Conclusion}

We propose that the use of visuals in the dissemination of the earnings news increases investor attention to that news. We examine firms' use of visuals to disseminate earnings news on Twitter and how this choice affects attention to the news. We capture the first stage of awareness in the cognition process, attention, using retweets of earnings-related tweets. We also examine the return outcomes at the end of the cognition process, after the information signal has been encoded, processed, and comprehended.

Consistent with the visual attention hypothesis's prediction that visual information attracts greater investor attention, we find that investor engagement, as proxied by retweets, is significantly higher when a firm uses visuals in its earnings tweet. This finding holds both at the firm and tweet levels. Importantly, this finding holds for earnings tweets sent by the same firm on the same day. Furthermore, we find both attention-focus and attention-dilution effects by firms issuing multiple tweets on the earnings announcement date. Multiple tweets focus investor attention on the firm but dilute attention to each tweet message.

Consistent with the return predictions of the visual attention hypothesis derived from limited attention theories, we find that the initial investor reaction to earnings news is stronger, and the post-announcement reaction is lower, when visuals are used to disseminate earnings news. The results also suggest that the effect of visuals is concentrated on high-distraction days when there are many earnings announcements by other firms. Visuals in the earnings announcement tweet are likely to help the firm's announcement stand out from other firm earnings announcements.

We also find some evidence suggesting that firms' use of visuals is influenced by a desire to emphasize news that makes firm performance or value look better to outsiders. Firms are more likely to use visuals when earnings exceed market expectations and when sales growth is high. The evidence does not support the alternative hypothesis that firms use visuals to signal more value relevant (i.e., more persistent) earnings. On the contrary, we find that the use of visuals is negatively associated with earnings persistence.

The return results corroborate the earnings persistence result by indicating that managers use visuals opportunistically. The managers exploit temporary good earnings news by using visuals to make the news more salient. Investor optimism about the good news leads to a sharp return reaction on the announcement date. Subsequently, when the investors realize that the good news is temporary, the post-announcement return reverses to correct the initial overreaction.

Overall, our evidence that the use of visuals is associated with investor attention to earnings news supports the SEC's contention that visuals encourage investor engagement. However, the evidence that visuals are associated with lower earnings persistence and a post-earnings announcement return reversal suggests that visuals do not 
necessarily improve investor understanding of firm financial performance. Owing to the fact that firms can exploit visuals to manage investor perceptions, the firms' use of visuals as a disclosure tool could be a double-edged sword in its effects on investor welfare.

\section{Appendix A}

\section{Examples of earnings-announcement-related messages with visuals}

Example 1 (Abbott Laboratories' message about its earnings announcement on July 22, 2015)

\$ABT reports Q2 results; adjusted earnings per share of 52 cents, exceeding analyst estimates.

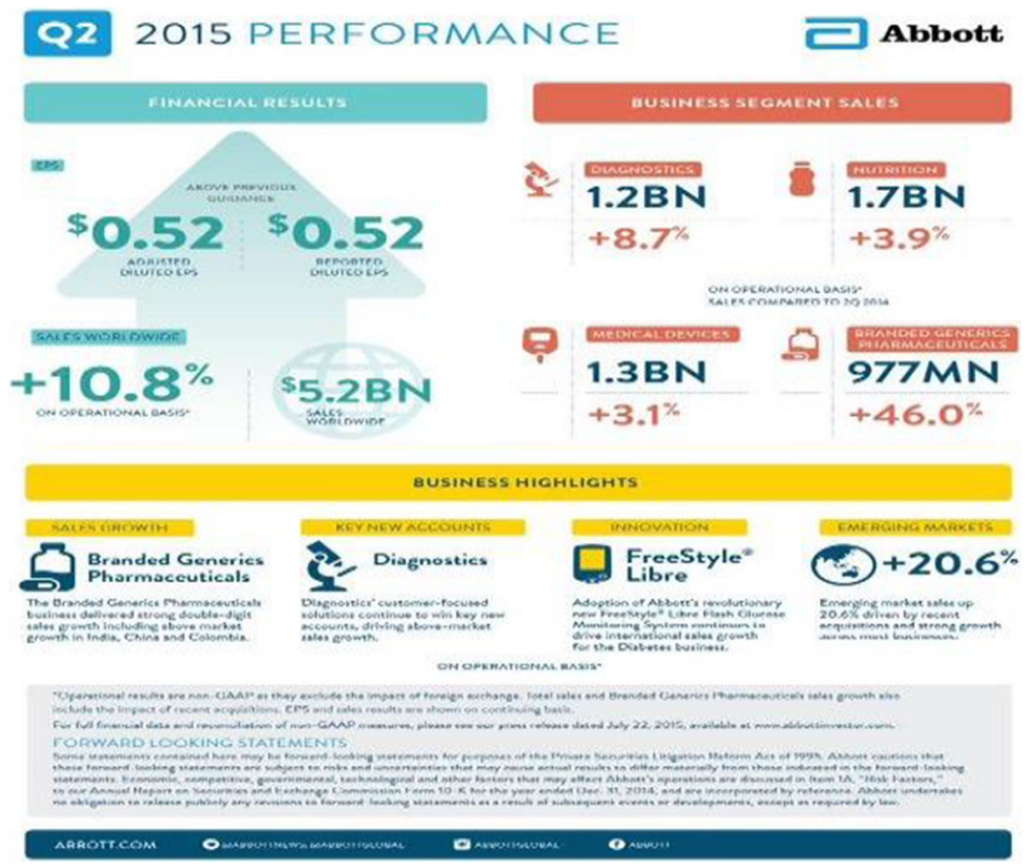


Example 2 (Newport Corp.'s message about its earnings announcement on July 30, 2014)

\$NEWP Q2 Earnings Call Highlights \#NEWPQ2.

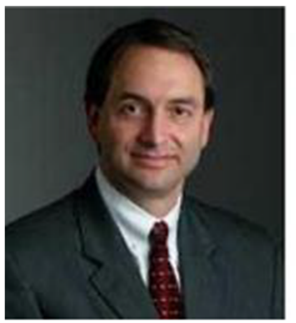

"Newport executed well in Q2 with sales of $\$ 153.2 \mathrm{M}$ representing $14.2 \%$ year-over-year growth"

Robert Phillippy, Chief Executive Officer Newport Corporation

D Nemport. tecenocen solitom

Example 3 (WPX Energy's message about its earnings announcement on August 5, 2015)

\$WPX reports 2Q 2015 results. Read more:

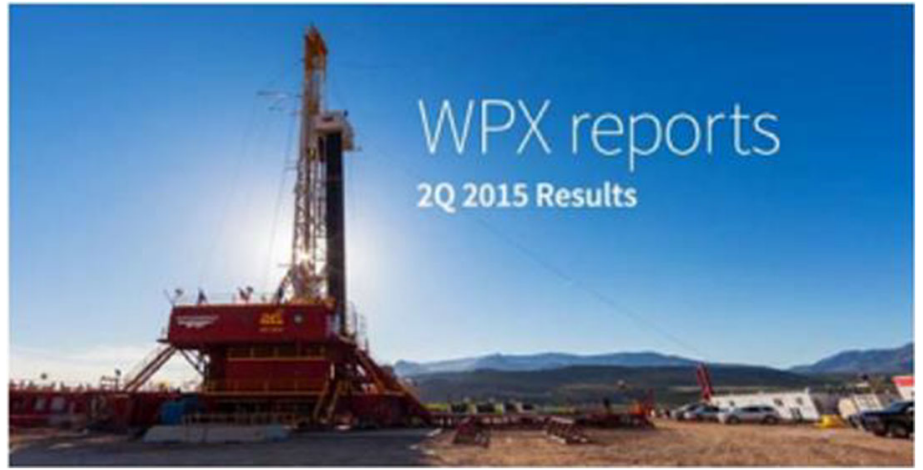

\section{Appendix B}

\section{Keywords}

The appendix provides the list of the keywords that we use to identify among all tweets sent on earnings announcement dates those tweets that are likely to be related to the earnings announcement

\begin{tabular}{lll}
\hline earnings & beats & Q1 \\
earning & dividend & Q2 \\
income & cash dividend & Q3 \\
revenue & forward-looking statement & Q4 \\
results & forward-looking statements & EPS \\
quarter & net income & profit \\
quarterly & common share & profits \\
press release & earnings forecast & sales \\
financial results & earnings forecasts & strong performance \\
earnings results & $1 Q$ & stock repurchases
\end{tabular}




\begin{tabular}{lll}
\hline earnings guidance & $2 \mathrm{Q}$ & GAAP \\
conference call & $3 \mathrm{Q}$ & non-GAAP \\
conf call & $4 \mathrm{Q}$ & profitability \\
sebcast & & $\begin{array}{l}\text { shareholder value } \\
\text { exceeds expectations }\end{array}$ \\
beat & & \\
\hline
\end{tabular}

\section{Appendix C}

\section{Variable definitions}

\section{Variable Description}

Twitter Variables at the Firm-Quarter Level

VISUALS An indicator variable that equals 1 if the firm sent at least one earnings-announcement-related tweet with visuals on the earnings announcement date, and 0 otherwise.

VISUALS.RES Residual visuals, calculated as the residuals from the first-stage OLS regression (3) with industry, year, and quarter fixed effects, where VISUALS is regressed on a set of its predicted determinants.

QUANT.ITEMS An indicator variable that equals 1 if the firm sent at least one earnings-announcement-related tweet on the earnings announcement date that contains quantitative information, and 0 otherwise.

WEB.LINKS

An indicator variable that equals 1 if the firm sent at least one earnings-announcement-related tweet on the earnings announcement date that contains a hyperlink that directs to an external website, and 0 otherwise.

RETWEETS

An indicator variable that equals 1 if at least one earnings-announcement-related tweet posted by the firm on the earnings announcement date was retweeted, and 0 otherwise.

FOLLOWERS

The natural logarithm of a firm's total number of Twitter followers as of March 31, 2018, the day we completed the data scraping of followers' information.

EA.TWEETS The number of earnings-announcement-related tweets on the earnings announcement date for the firm for the quarter.

LENGTH

The natural logarithm of the average number of characters of the earnings-related tweets on the earnings announcement date for the firm for the quarter.

Twitter Variables at the Tweet Level

VISUALS $S_{\text {tweet.level }} \quad$ An indicator variable that equals 1 if the earnings-announcement-related tweet contains visuals (still images or videos), and 0 otherwise.

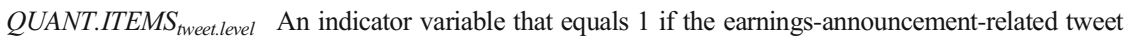
contains quantitative information, and 0 otherwise.

WEB.LINKS $S_{\text {tweet.level }}$

An indicator variable that equals 1 if the earnings-announcement-related tweet contains a hyperlink, and 0 otherwise.

RETWEETS $_{\text {tweet.level }}$ An indicator variable that equals 1 if the earnings-announcement-related tweet was retweeted, and 0 otherwise.

LENGTH $H_{\text {tweet.level }} \quad$ The natural logarithm of the number of characters of the earnings-related tweet.

Other Variables

POS.SURP

An indicator of positive earnings surprise that equals to 1 if actual earnings for the quarter are greater than or equal to the consensus analyst forecast, and 0 otherwise. 
Variable

GROWTH

SUE

RSUE

SIZE

STD.GROWTH

NEG.GROWTH

BTM

ANA.FOLLOW

EARN

STD.EARN

LOSS

INST.OWN

\#EA

NRANK

CAR $(-1,+1)$

CAR $(-1,+1)_{\text {NEXT.QTR }}$

AB.SEARCH

Lagged AB.SEARCH

MEDIA.COVERAGE
Description

The consensus analyst forecast is the mean of the most recent forecasts made by individual analysts.

Sales growth, calculated as the percentage change in quarterly sales from the same quarter last year.

Unexpected earnings, calculated as actual quarterly earnings as reported by $\mathrm{I} / \mathrm{B} / \mathrm{E} / \mathrm{S}$ minus the consensus analyst forecast, scaled by stock price at the end of the previous fiscal quarter. The consensus analyst forecast is the mean of the most recent forecasts made by individual analysts.

The decile rank of unexpected earnings, $S U E$, scaled such that it varies from 0 (for the bottom decile) to 1 (for the top decile).

The natural logarithm of the market value of equity at the end of the previous fiscal quarter.

The standard deviation of sales growth, GROWTH, over the last eight quarters.

An indicator variable that equals 1 if the quarterly sales growth from the same quarter last year is negative, and 0 otherwise.

The book-to-market ratio at the end of the previous fiscal quarter.

Analyst following, calculated as the natural logarithms of one plus the number of analysts that have outstanding earnings forecast for the firm for the quarter.

Quarterly earnings before extraordinary items scaled by the average total assets.

The standard deviation of $E A R N$ measured over the last eight quarters.

An indicator variable that equals 1 if the quarterly earnings before extraordinary items are negative, and 0 otherwise.

Institutional ownership, calculated as the fraction of firm shares owned by institutional investors.

The number of same-day earnings announcements by other firms.

The quartile rank of the number of the same-day earnings announcements by other firms.

The cumulative abnormal return over the three-day window centered on the earnings announcement date, where daily abnormal returns are raw stock returns minus the market value-weighted return.

The cumulative abnormal return, $C A R(-1,+1)$, around the next earnings announcement day.

Abnormal Google search volume for the firm for the day, calculated as the difference between the Google search volume for the firm for the day and the average Google search volume for the same firm and weekday over the previous ten weeks, scaled by the average Google search volume for the same firm and weekday over the previous ten weeks (Drake et al. 2012).

Abnormal Google search volume, AB.SEARCH, for the firm for the previous day.

Media coverage, calculated as the natural logarithm of one plus the number of news articles for the firm for the day, where the number of articles is obtained from Bloomberg.

Open Access This article is licensed under a Creative Commons Attribution 4.0 International License, which permits use, sharing, adaptation, distribution and reproduction in any medium or format, as long as you give appropriate credit to the original author(s) and the source, provide a link to the Creative Commons licence, and indicate if changes were made. The images or other third party material in this article are included in the article's Creative Commons licence, unless indicated otherwise in a credit line to the material. If material is not included in the article's Creative Commons licence and your intended use is not permitted by statutory 
regulation or exceeds the permitted use, you will need to obtain permission directly from the copyright holder. To view a copy of this licence, visit http://creativecommons.org/licenses/by/4.0/.

\section{References}

Asay, H.S., R. Libby, and K. Rennekamp. (2018). Do features that associate managers with a message magnify investors' reactions to narrative disclosures? Accounting, Organization, and Society. 68: 1-14.

Barber, B., and T. Odean. (2008). All that glitters: The effect of attention and news on the buying behavior of individual and institutional investors. Review of Financial Studies. 21: 785-818.

Bartov, E., L. Faurel, and P. Mohanram. (2018). Can twitter help predict firm-level earnings and stock returns? The Accounting Review. 93: 25-57.

Beattie, V., and M. Jones. (2008). Corporate reporting using graphs: A review and synthesis. Journal of Accounting Literature. 27: 71-110.

Bernard, V., and J. Thomas. (1990). Evidence that stock prices do not fully reflect the implications of current earnings for future earnings. Journal of Accounting and Economics. 13: 305-340.

Bertrand, M., D. Karlan, S. Mullainathan, E. Shafir, and J. Zinman. (2010). What's Advertising Content Worth? Evidence from a Consumer Credit Marketing Field Experiment. The Quarterly Journal of Economics. 125 (1): 263-306.

Blankespoor, E., E. deHaan, and C. Zhu. (2018). Capital market effects of media synthesis and dissemination: Evidence from robo-journalism. Review of Accounting Studies. 23: 1-36.

Blankespoor, E., E. deHaan, J. Wertz, and C. Zhu. (2019). Why do individual investors disregard accounting information? The roles of information awareness and acquisition costs. Journal of Accounting Research. 57: 53-84.

Blankespoor, E., G. Miller, and H. White. (2014). The role of dissemination in market liquidity: Evidence from firms' use of twitter ${ }^{\mathrm{TM}}$. The Accounting Review. 89: 79-112.

Bowen, R., A. Davis, and D. Matsumoto. (2005). Emphasis on pro forma versus GAAP earnings in quarterly press releases: Determinants, SEC intervention, and market reactions. The Accounting Review. 80: 10111038.

Brown, N., B. Elliott, and W. Grant. (2019). Gaming regulation with image-based tweets. Working paper.

Brown, S., X. Tian, and J. Wu Tucker. 2018. The spillover effect of SEC comment letters on qualitative corporate disclosure: Evidence from the risk factor disclosure. Contemporary Accounting Research. 35 : $622-656$.

Bushee, B., I. Gow, and D. Taylor. (2018). Linguistic complexity in firm disclosures: Obfuscation or information? Journal of Accounting Research. 56: 85-121.

Chawla, N., Z. Da, J. Xu, and M. Ye. (2014). Catching fire: An anatomy of information diffusion using retweets. Working paper.

Chun, H., H. Kwak, Y. Eom, Y. Ahn, S. Moon, and H. Jeong. (2008), October. Comparison of online social relations in volume vs interaction: A case study of cyworld. In proceedings of the 8th ACM SIGCOMM conference on internet measurement: 57-70.

Counts, S., and K. Fisher. (2011). Taking it all in? Visual attention in microblog consumption. Fifth international AAAI conference on weblogs and social media: 97-104.

Cox, R., P. Goeij, and G. Campenhout. (2018). Are pictures worth a thousand words? Infographics and investment decision making. Working paper. Available at https://papers.ssrn.com/sol3/papers.cfm? abstract_id=3277502.

Crowley, R., W. Huang, and H. Lu. (2018). Discretionary dissemination on twitter. Working paper. Available at https://papers.ssrn.com/sol3/papers.cfm?abstract_id=3105847.

Curtis, A., V. Richardson, and R. Schmardebeck. (2014). Investor attention and the pricing of earnings news. Working paper, University of Washington. Available at http://papers.ssrn.com/sol3/papers.cfm?abstract $\mathrm{id}=2467243$.

Da, Z., J. Engelberg, and P. Gao. (2011). In search of attention. Journal of Finance. 66: 1461-1499.

DellaVigna, S., and J. Pollet. (2009). Investor inattention and Friday earnings announcements. Journal of Finance. 64: 709-749.

Demers, E., and C. Vega. (2011). Linguistic tone in earnings announcements: News or noise? Working paper, FRB International Finance Discussion Paper.

Dichev, I., and V. Tang. (2009). Earnings volatility and earnings persistence. Journal of Accounting and Economics. 47: 160-181. 
Drake, M.S., D. Roulstone, and J. Thornock. (2012). Investor information demand: Evidence from Google searches around earnings announcements. Journal of Accounting Research. 50 (4): 1001-1040.

Elliott, W., S. Grant, and K. Rennekamp. (2017). How disclosure features of corporate social responsibility reports interact with investor numeracy to influence investor judgments. Contemporary Accounting Research. 34: 1596-1621.

Elliott, W., F. Hodge, and L. Sedor. (2012). Using online video to announce a restatement: Influences on investment decisions and the mediating role of trust. The Accounting Review. 87: 513-535.

Engelberg, J., C. Sasseville, and J. Williams. (2012). Market madness: The case of mad money. Management Science. 58: 351-364.

Files, R., E. Swanson, and S. Tse. (2009). Stealth disclosure of accounting restatements. The Accounting Review. 84: 1495-1520.

Fiske, S., and S. Taylor. (2016). Social cognition, from brains to culture. McGraw-Hill.

Guay, W., D. Samuels, and D. Taylor. (2016). Guiding through the fog: Financial statement complexity and voluntary disclosure. Journal of Accounting and Economics. 62: 234-269.

Guindy, M., J. Naughton, and R. Riordan. (2020). The chilling effect of regulation FD: Evidence from SEC endorsement of social media. Working paper. Available at: https://ssrn.com/abstract=3385180 .

Huff, D. (1954, 1991). How to lie with statistics. W. W. Norton \& Company. New York, NY.

Jung, M., J. Naughton, A. Tahoun, and C. Wang. (2018). Do firms strategically disseminate? Evidence from corporate use of social media. The Accounting Review. 93: 225-252.

Ham, C., N. Seybert, and S. Wang. (2018). Narcissism is a bad sign: CEO signature size, investment, and performance. Review of Accounting Studies. 23: 234-264.

Hayn, C. (1995). The information content of losses. Journal of Accounting and Economics. 20: 125-153.

Hirshleifer, D., S. Lim, and S.H. Teoh. (2009). Driven to distraction: Extraneous events and underreaction to earnings news. Journal of Finance. 64: 2287-2323.

Hirshleifer, D., S. Lim, and S.H. Teoh. (2011). Limited investor attention and stock market misreactions to accounting information. Review of Asset Pricing Studies. 1: 35-73.

Hirshleifer, D., and S.H. Teoh. (2003). Limited attention, information disclosure, and financial reporting. Journal of Accounting and Economics. 36: 337-386.

Hockley, W. (2008). The picture superiority effect in associative recognition. Memory \& Cognition. 36: 13511359.

Hou, K., L. Peng, and W. Xiong. (2009). A tale of two anomalies: The implication of investor attention for price and earnings momentum. Working paper: Ohio State University.

Huang, X., A. Nekrasov, and S.H. Teoh. (2018). Headline salience, managerial opportunism, and over- and underreactions to earnings. The Accounting Review. 93: 231-255.

Huang, X., S.H. Teoh, and Y.L. Zhang. (2014). Tone management. The Accounting Review. 89: 1083-1113.

Klibanoff, P., O. Lamont, and T.A. Wizman. (1998). Investor reaction to salient news in closed-end country funds. Journal of Finance. 53: 673-699.

Kwak, H., C. Lee, H. Park, and S. Moon. (2010). What is twitter, a social network or a news media? Proceedings of the 19th international conference on world wide web: 591-600.

Lawrence, A. (2013). Individual investors and financial disclosure. Journal of Accounting and Economics. 56: $130-147$.

Lee, L., A. Hutton, and S. Shu. (2015). The role of social media in the capital market: Evidence from consumer product recalls. Journal of Accounting Research. 53: 367-404.

Levi, Y. (2015). Information architecture and intertemporal choice: A randomized field experiment in the United States. Working paper: UCLA.

Li, F. (2008). Annual report readability, current earnings, and earnings persistence. Journal of Accounting and Economics. 45: 221-247.

Li, F. (2011). Textual analysis of corporate disclosures: A survey of the literature. Journal of Accounting Literature. 29: 143-165.

Li, J., and J. Yu. (2012). Investor attention, psychological anchors, and stock return predictability. Journal of Financial Economics. 104: 401-419.

Loughran, T., and B. McDonald. (2017). The use of EDGAR filings by investors. Journal of Behavioral Finance. 18: 231-248.

Lou, D. (2014). Attracting investor attention through advertising. Review of Financial Studies 27: 1797-1829.

Madsen, J., and J. McMullin. (2020). Economic consequences of risk disclosures: Evidence from crowdfunding. The Accounting Review. 95: 331-363.

Mayew, W., and M. Venkatachalam. (2012a). Speech analysis in financial markets. Foundations and Trends in Accounting. 7: 73-130. 
Mayew, W., and M. Venkatachalam. (2012b). The power of voice: Managerial affective states and future firm performance. Journal of Finance. 67: 1-44.

Merkley, K.J. (2014). Narrative disclosure and earnings performance: Evidence from R\&D disclosures. The Accounting Review. 89: 725-757.

Peress, J. (2014). The media and the diffusion of information in financial markets: Evidence from newspaper strikes. Journal of Finance. 69: 2007-2043.

Potter, M., B. Wyble, C. Hagmann, and E. McCourt. (2014). Detecting meaning in RSVP at 13 ms per picture. Attention, Perception, \& Psychophysics. 76: 270-279.

Rakowski, D., S.E. Shirley, and J.R. Stark. (2021). Twitter activity, investor attention, and the diffusion of information. Financial Management. 50 (1): 3-46.

Securities and Exchange Commission. (1998). A plain English handbook. How to create clear SEC disclosure documents. Office of Investor Education and Assistance, SEC, Washington, DC. Available at https:// www.sec.gov/pdf/handbook.pdf .

Shepard, R. (1967). Recognition memory for words, sentences, and pictures. Journal of Memory and Language. 6: 156-163.

Teoh, S. (2018). The promise and challenges of new datasets for accounting research. Accounting, Organizations and Society. 68: 109-117.

Tufte, E. (1983, 2001). The visual display of quantitative information. Graphics Press, Cheshire, CT.

Yuan, Y. (2015). Market-wide attention, trading, and stock returns. Journal of Financial Economics. 116: $548-564$.

Zhu, C. (2018). Investor demand for contextual information: Evidence from Wikipedia. Working paper.

Publisher's note Springer Nature remains neutral with regard to jurisdictional claims in published maps and institutional affiliations. 